\title{
Equilibrium Search and Tax Credit Reform
}

by

Andrew Shephard, Princeton University

CEPS Working Paper No. 223

September 2011 


\title{
Equilibrium Search and Tax Credit Reform
}

\author{
Andrew Shephard* \\ September 27, 2011
}

\begin{abstract}
An empirical equilibrium job search model with wage posting is developed to analyze the labor market impact of UK tax reforms. The model allows for a rich characterization of the labor market, with hours responses, accurate representations of the tax and transfer system, and both worker and firm heterogeneity. The model is estimated with pre-reform longitudinal survey data using a semi-parametric estimation technique, and the impact of actual tax reform policies is simulated. The model predicts that the British Working Families' Tax Credit and contemporaneous reforms increased employment, with equilibrium effects found to play a relatively minor role.
\end{abstract}

Keywords: Labour market equilibrium, job search, wage dispersion, unemployment, monopsony, incidence, tax credits

Over the past two decades earned income tax credit programs have grown substantially in the UK, US and many other countries. ${ }^{1}$ These programs are typically motivated by a desire from policy makers to increase labor market participation among target groups, and to alleviate in-work poverty. While the effect of these policies on labor supply has been studied extensively, much less is known regarding the incidence of these tax credit programs and their broader equilibrium impact. ${ }^{2}$ The objective of this paper

*Princeton University, 203 Fisher Hall, Department of Economics, Princeton University, Princeton, NJ 08544 (email: ajshep@princeton.edu). I am indebted to Jean-Marc Robin for his extensive advice and support. I am also grateful to Richard Blundell, Kirill Evdokimov, Guy Laroque, Costas Meghir, Morten Ravn, and numerous seminar participants for useful comments. Material from the Quarterly Labour Force Survey is crown copyright and has been made available by the Office for National Statistics through the Economic and Social Data Service. Crown copyright material is reproduced with the permission of the Controller of HMSO and the Queen's Printer for Scotland. The Office for National Statistics and the Economic and Social Data Service bear no responsibility for the analysis or interpretation.

${ }^{1}$ See Hotz and Scholz (2003) for EITC in the US, and Blundell and Hoynes (2004) for the British WFTC and its predecessors.

${ }^{2}$ Exceptions include the recent studies by Azmat (2006), Leigh (2010), and Rothstein (2008, 2009). 
is to develop an empirical equilibrium job search model that provides us with an appropriate framework to address these issues, and to apply it in our analysis of a series of UK tax reforms that included the Working Families' Tax Credit (WFTC) reform, which considerably increased the generosity of in-work support for families with children (see Brewer, 2001).

This paper contributes to the literature on the impact of tax credit policies, but starts from the premise that labor markets may be characterized by considerable search frictions (see for example, van den Berg and Ridder, 2003). The presence of frictions may have important implications for our understanding of programs like WFTC. In particular, if firms set wages then these frictions bestow them with some degree of monopsony power. If labor supply were to increase following such reforms, firms may respond by lowering wage offers, in which case the effective transfer to eligible families is reduced, whilst non-eligible families may become worse off if they are competing within the same labor market. In terms of both evaluation, and program design, an understanding of the quantitative importance of these equilibrium effects is essential.

The equilibrium job search literature allows us to capture these and other effects in a dynamic and imperfectly competitive economy that is characterized by search frictions. Here it is the competition between firms that is the fundamental determinant of wages, with the extent of this competition limited by the presence of search frictions. In the spirit of Burdett and Mortensen (1998), we consider a model with ex-ante wage posting: firms set wages before meeting potential workers, which workers then either accept or reject. ${ }^{3}$ We advance this literature in several dimensions, with the model developed here designed to reflect some key features of the UK labor market and to allow for the possibility of rich equilibrium effects following reforms such as WFTC.

At a methodological level, this paper contributes to the empirical equilibrium search literature by developing a wage-posting model with hours responses, accurate representations of the tax and transfer system, and both worker and firm heterogeneity. The paper most closely related is the on-the-job search model presented in Bontemps, Robin

\footnotetext{
${ }^{3}$ Manning (2003) argues that while wage posting is not always appropriate, it provides a good characterization of wage determination in many settings. This is likely to be particularly true when focusing on low-skilled labor markets, as in this paper. Hall and Krueger (2008) present recent US survey evidence which suggests that while other forms of wage formation are also important, wage posting is much more prevalent in less skilled occupations (see also the discussion in Manning, 2003, chapter 5). Other papers have examined the impact of similar policies with alternative forms of wage determination; Lise, Seitz and Smith (2005) simulate the effect of a wide scale implementation of the Canadian Self-Sufficiency Project in a model with ex-post worker-firm bargaining. They find substantial equilibrium effects, which reverse the positive cost-benefit conclusions of their partial equilibrium evaluation.
} 
and van den Berg (1999), which this paper builds upon. As in their model, we allow for continuous distributions of firm productivity and worker leisure flows, but do not impose the over-identifying restriction that the arrival rate of job offers is independent of employment status. ${ }^{4}$ Furthermore, we endogenize these job offer arrival rates at the macroeconomic level by complementing the model with aggregate matching functions. As will become clear, allowing for heterogeneity in worker leisure flows is important as it provides the main mechanism through which tax reforms induce non-degenerate labor supply responses.

As we describe in the following section, both WFTC and its predecessor were only available to families with children. To investigate possible differential impacts to the tax reforms, and to also explain differences in labor market outcomes, we incorporate further dimensions of worker heterogeneity. Both the tax and transfer system, and the key worker structural parameters, may all potentially vary with observable demographic characteristics. In contrast to the segmented markets approach adopted by van den Berg and Ridder (1998), we will allow workers of all types to operate within the same labor market. It is this feature that allows workers who are not eligible for tax credits to be indirectly affected by them through changes in the optimal strategies of firms.

The UK labor market has a high prevalence of part-time work, particularly among women with children. As noted above, the presence of children is a central eligibility requirement for receipt of tax credits. These features motivate us to incorporate hours of work into the model. While the use of the canonical labor supply model may be pervasive, there is a body of empirical work that challenges the view that individuals are able to freely choose their hours of work at a fixed hourly wage. ${ }^{5}$ That jobs sequentially arrive as wage-hours packages is an assumption that will be maintained throughout this paper. We do not attempt to provide micro-foundations for this, but rather assume it is a purely technological characteristic of firms.

The level of generality here means that the model is analytically intractable. Nonetheless, we show that the model remains empirically tractable by developing a three step semi-parametric estimation technique similar to that proposed by Bontemps, Robin and

\footnotetext{
${ }^{4}$ As we shall see in Section 2, this over-identifying restriction simplifies the analysis as it implies that the optimal strategy of unemployed workers is independent of the equilibrium wage offer distribution. This restriction led to a poor fit of the duration data in their application, as empirically job arrival rates for unemployed workers are often estimated to exceed that of the employed.

5See, for example, Altonji and Paxson (1988). Blundell, Brewer and Francesconi (2008) studied the impact of a series of in-work benefit reforms in the UK during the 1990s, and found that the positive effect on hours worked was largely driven by women who changed their job.
} 
van den Berg (1999, 2000), and then estimating the model using UK Labour Force Survey data shortly before WFTC was introduced. Using the estimated structural parameters we then simulate the impact of actual tax reforms. We find that the introduction of WFTC, together with the contemporaneous changes to the tax and transfer system, increased employment for most groups, with single parents experiencing the largest employment increase. Our main simulations suggest that while equilibrium considerations do play a role in these reforms, the changes in labor market outcomes are dominated by the direct effect of changing job acceptance behavior.

The remainder of the paper proceeds as follows. In the next section we describe the WFTC reform, as well as the contemporaneous changes to the UK tax and transfer system. In Section 2 we present the model and describe the optimal strategies of firms and workers. Section 3 discusses identification, describes the estimation procedure, and presents the main estimation results. In Section 4 we then use the estimated model to simulate the impact of actual tax reforms. Finally, Section 5 concludes.

\section{UK Tax Credit Reform}

As in the US, the UK has a long history of in-work benefits, starting with the introduction of Family Income Supplement in 1971. Over the years, these programs became more generous, and in October 1999, Working Families' Tax Credit was introduced, replacing a similar but less generous tax credit program called Family Credit (FC). Both WFTC and FC were only available to families with children and shared a similar eligibility structure, requiring recipients work for at least 16 hours per week, and with the credit tapered away with household earnings above a threshold. Both also offered a further credit when recipients worked at least 30 hours a week. WFTC increased the level of in-work support by offering higher credits, increasing the threshold so that families can earn more before it was phased out, and by reducing the withdrawal rate. ${ }^{6}$ In Figure 1 we illustrate how this reform changed tax credit awards for a single parent family.

When analyzing low income support it is important to take an integrated view of the tax system. This is because tax credit awards in the UK are counted as income when calculating entitlements to other benefits. Families in receipt of these benefits would gain less from WFTC than otherwise equivalent families not receiving such benefits. There

\footnotetext{
${ }^{6}$ WFTC also provided more support for formal childcare costs and allowed all child maintenance payments to be disregarded from income when calculating tax credit entitlement.
} 


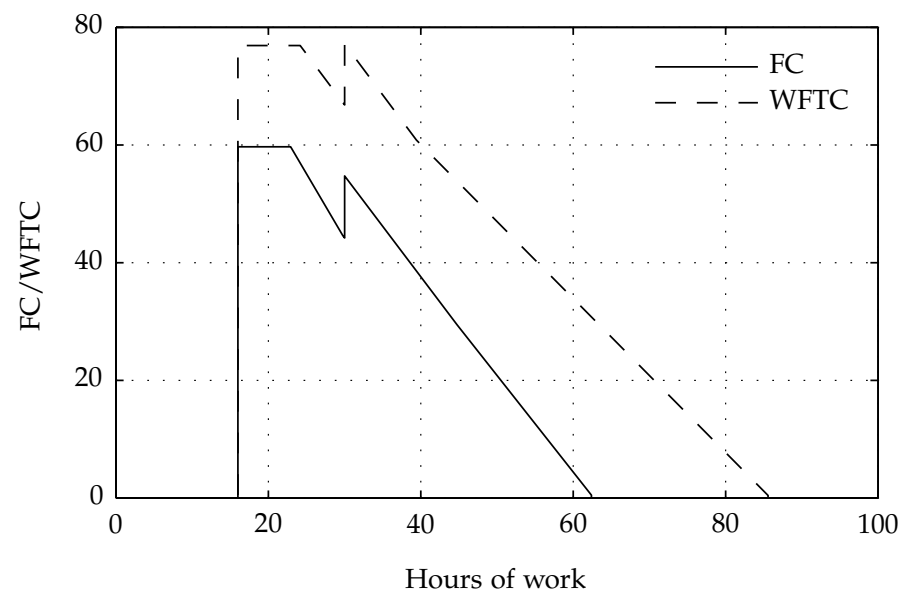

Figure 1: Tax Credit awards under FC and WFTC. FC refers to Family Credit as of April 1997. WFTC refers to Working Families Tax Credit as of April 2002. Figure assumes a lone parent with a single child aged 10, and a constant hourly wage rate of $£_{3.50}$. All incomes expressed in pounds per week in April 1997 prices.

were also other important changes to the tax system affecting families with children that coincided with the expansion of in-work tax credits, and which make the potential labor market impact considerably more complex. In particular, there were increases in the generosity of Child Benefit (a cash benefit available to all families with children regardless of income), as well as notable increases in the child additions in Income Support (a welfare benefit for low income families working less than 16 hours a week). There were also other changes to the tax and transfer system that affected families both with and without dependent children: a new 10\% starting rate of income tax was introduced, the basic rate of income tax was reduced from $23 \%$ to $22 \%$, and there was a real rise in the point at which National Insurance (payroll tax) becomes payable. ${ }^{7}$

\section{The Model}

We now describe the theoretical model that we use to study the impact of tax reforms. In this model, the economy consists of a continuum of individuals with a population size normalized to unity. Individuals firstly differ by their observable demographic characteristics that are finite in number and indexed by $i \leq I$. The fraction of such workers

\footnotetext{
${ }^{7}$ Our analysis does not consider the non-tax related changes that occurred during this period. Various "New Deal" active labor market policies were introduced which aimed to improve both the incentives and the ability of the long-term unemployed to obtain employment (see Blundell et al., 2004). Furthermore, a national minimum wage was introduced (see Metcalf, 2008).
} 
is denoted $n_{i}$ with $\sum_{i} n_{i}=1$. Individuals also differ in their unobserved leisure flow $b$, which includes any search costs but not unemployment benefit and other transfers. The cumulative distribution function of leisure flows in the population of type $i$ workers is denoted $H_{i}$, which is assumed continuous on its support $\left[\underline{b}_{i}, \bar{b}_{i}\right]$. To simplify some of the subsequent exposition we assume that $\underline{b}_{i}$ is sufficiently low such that in equilibrium all firms are active in the labor market. Time is continuous and individuals live forever with the constant discount rate $\rho_{i}>0$. There is no saving or borrowing technology.

Jobs are characterized by a wage rate $w$ and required hours of work $h$. We allow for part-time jobs (hours $h_{0}$ ) and full-time jobs (hours $h_{1}>h_{0}$ ), with workers subject to a monetary hours disutility $C_{i}^{h}{ }^{8}$ Mirroring the actual conditioning performed by the UK tax authorities, the tax schedule is a function of demographics, hours, and earnings, with $T_{i}^{h}(w h)$ denoting the potentially negative net taxes paid by an employed worker. We assume that this tax schedule is continuously differentiable in labor earnings. The net transfer paid to an unemployed worker is given by $-T_{i}^{u}$. Utility flows are assumed linear in income, so that in the presence of a tax and transfer system and hours responses these are given by:

$$
\begin{array}{ll}
w h-T_{i}^{h}(w h)-C_{i}^{h} & \text { if employed } \\
b-T_{i}^{u} & \text { if unemployed. }
\end{array}
$$

From the outset we impose the location normalization $C_{i}^{0}=0$ for all $i \leq I$.

\subsection{Worker Search}

Individuals (or workers) are either employed or unemployed. Both search for jobs. Job offer arrivals are exogenous to the worker: a type $i$ worker accrues hours $h$ offers at the constant rate $\lambda_{j i}^{h}$ with $j \in\{u, e\}$ indexing the current worker state of unemployment or employment. To maintain focus on the decision of workers, we postpone any discussion concerning how these arrival rates may depend upon the overall state (or tightness) of the labor market until Section 2.5.9 Employment spells end at rate $\delta_{i}$ regardless of

\footnotetext{
${ }^{8}$ The inclusion of work hours is rare in the empirical search literature (for an exception see, for example, Blau, 1991). The analytical framework we develop generalizes to more than two hours choices, and can also be applied in the context of other non-wage amenities. See also Hwang, Mortensen and Reed (1998) for an analysis of non-wage amenities in an equilibrium search framework.

${ }^{9}$ We do not allow the search effort of workers to vary with their current wage or to respond to any changes in the tax system. A more realistic approach would endogenize the job offer arrival rates at the micro-level by relating them directly to an endogenously determined worker search effort, as in Christensen et al. (2005). Incorporating such responses is non-trivial and is left as an extension for future research. See Gentry and Hubbard (2004) for US evidence on the impact of tax rates on job mobility.
} 
whether individuals are employed in part-time or full-time jobs, and we define $\kappa_{j i}^{h}=$ $\lambda_{j i}^{h} / \delta_{i}$ as the ratio of the arrival rates to this destruction rate. ${ }^{10}$ We place no restrictions on the relative magnitude of these parameters, but note that the assumption that both the job destruction rate and job offer arrival rates when employed are independent of whether individuals are currently engaged in part-time or full-time work, is an overidentifying restriction that simplifies the subsequent analysis.

Regardless of their observed or unobserved type, workers sample sector $h$ wages from the wage offer distribution $F_{h}$ which has support $\left[\underline{w}_{h}, \bar{w}_{h}\right]$. Wages are assumed constant throughout an individual's employment spell within a given firm and we additionally define $\bar{F}_{h} \equiv 1-F_{h}$. For now, we treat these distributions as given and will later describe how they emerge as an equilibrium outcome from the wage posting game. The assumption that all workers sample offers from common distributions implies that, while the government may be able to condition taxes and transfers on demographic characteristics, firms are unable to do so. This assumption can be justified by the presence of anti-discrimination laws, such as the Equal Pay Act 1970, Sex Discrimination Act 1975, and various Employment Equality Regulations, which outlaw such practices.

\subsection{Worker Strategies}

We now describe the optimal strategies of unemployed and employed workers. To proceed we define $q_{i}(w)$ such that the value to a type $i$ individual holding a full-time job paying wage $w$ is the same as the value of a part-time job paying wage $q_{i}(w)$. We refer to this function as the indifference condition.

Proposition 1 The indifference condition $q_{i}(w)$ solves:

$$
w h_{1}-T_{i}^{1}\left(w h_{1}\right)-C_{i}^{1}=q_{i}(w) h_{0}-T_{i}^{0}\left(q_{i}(w) h_{0}\right)
$$

This function describes the wedge between the wages that an individual will accept across hours sectors. For example, a full-time wage $w$ worker will accept any full-time offer that is (by convention, strictly) greater than $w$; they will also accept any part-time offer (strictly) greater than $q_{i}(w)$. The proof of the proposition follows immediately from the assumption that the job destruction rate and job offer arrival rates are independent

\footnotetext{
${ }^{10}$ As emphasized by van den Berg and Ridder (2003), the parameters $\kappa_{e i}^{h}$ and $\kappa_{u i}^{h}$ can be thought of as labor market friction parameters. In particular, $\kappa_{e i}^{h}$ is the number of sector $h$ job offers a type $i$ individual can expect to receive when employed, before exiting to unemployment.
} 
of current hours; employed workers can do no better than maximize their instantaneous utility flow. ${ }^{11}$ Note that $q_{i}(w)$ has a unique solution provided that marginal tax rates are strictly less than one for all $w$, conditional on hours of work. We maintain this assumption throughout.

Unemployed workers follow a reservation wage strategy. Let $\phi_{i}(b)$ denote the lowest acceptable wage for full-time work conditional on observed type $i$ and unobserved leisure flow $b$. This takes a similar form to the standard reservation wage equation with on-the-job search (see Mortensen and Neumann, 1988), but is here modified both by the presence of taxes (which discount future earnings by the net-of-tax rate) and because workers are sampling job offers from two distributions.

Proposition 2 The full-time reservation wage for unemployed workers $\phi_{i}(b)$ is the solution to the following equation:

$$
\phi_{i}(b) h_{1}-T_{i}^{1}\left(\phi_{i}(b) h_{1}\right)-C_{i}^{1}=b-T_{i}^{u}+h_{1} \int_{\phi_{i}(b)}^{\infty} B_{i}(w) d w
$$

where:

$$
B_{i}(w) \equiv \frac{\left(1-T_{i}^{1^{\prime}}\left(w h_{1}\right)\right)\left[\left(\kappa_{u i}^{0}-\kappa_{e i}^{0}\right) \bar{F}_{0}\left(q_{i}(w)\right)+\left(\kappa_{u i}^{1}-\kappa_{e i}^{1}\right) \bar{F}_{1}(w)\right]}{1+\rho_{i} / \delta_{i}+\kappa_{e i}^{0} \bar{F}_{0}\left(q_{i}(w)\right)+\kappa_{e i}^{1} \bar{F}_{1}(w)} .
$$

The proof of this proposition is provided in the Supplementary Material. We immediately establish the following corollary.

Corollary $\mathbf{I}$ The part-time reservation wage for unemployed workers is given by $q_{i}\left(\phi_{i}(b)\right)$.

Henceforth, we will refer to the full-time reservation wage for unemployed workers simply as the reservation wage. Before proceeding we note that when job offer arrival rates are independent of employment status, that is $\kappa_{u i}^{h}=\kappa_{e i}^{h}$, we have $B_{i}(w)=0$ for all $w$ so that the optimal strategy of workers is independent of the equilibrium wage offer distributions. This is the case analyzed in Bontemps, Robin and van den Berg (1999).

\subsection{Steady-state Worker Flows}

Having described the strategy of workers, we can derive a number of steady state conditions that characterize the labor market. For now, we continue to treat the distributions of wage offers and their arrival rates as being given.

\footnotetext{
${ }^{11}$ In the more general case where arrival rates and/or job destruction rates vary with current work hours, the indifference condition will be a function of the distribution of wage offers in both sectors.
} 


\subsubsection{Distribution of Reservation Wages}

Reservation wages summarize the optimal strategy of individuals. The cumulative distribution function of reservation wages amongst all type $i$ workers (both employed and unemployed) is denoted $A_{i}$ and is related to the distribution of unobserved leisure flows according to $A_{i}(w)=H_{i}\left(\phi_{i}^{-1}(w)\right)$. The respective distributions amongst the stock of unemployed and employed workers are denoted $A_{u i}$ and $A_{e i}$. These are related to $A_{i}$ according to:

$$
A_{i}(w)=u_{i} A_{u i}(w)+\left(1-u_{i}\right) A_{e i}(w)
$$

The distribution of reservation wages amongst the unemployed $A_{u i}$ allows us to describe the flows from the unemployment pool into employment at a given wage. As we demonstrate shortly, it also allows us to determine the steady state unemployment rate. In steady state the flow of individuals with a reservation wage no greater than $\phi$ who exit the employment pool following a job destruction shock must exactly equal the flow of such workers who enter employment. Hence,

$$
\delta_{i}\left(1-u_{i}\right) A_{e i}(\phi)=\lambda_{u i}^{0} u_{i} \int_{-\infty}^{\phi} \bar{F}_{0}\left(q_{i}(w)\right) d A_{u i}(w)+\lambda_{u i}^{1} u_{i} \int_{-\infty}^{\phi} \bar{F}_{1}(w) d A_{u i}(w)
$$

By differentiating equation 4 using Leibniz's rule we obtain a relationship between the densities of employed and unemployed worker reservation wages, which when combined with equation 3 allows us to establish the following proposition:

Proposition 3 The unemployment weighted distribution of reservation wages amongst type $i$ unemployed workers is given by:

$$
u_{i} A_{u i}(\phi)=\int_{-\infty}^{\phi} \frac{d A_{i}(w)}{1+\mathcal{D}_{u i}(w) / \delta_{i}(w)}
$$

where $\mathcal{D}_{u i}(\phi) \equiv \lambda_{u i}^{0} \bar{F}_{0}\left(q_{i}(\phi)\right)+\lambda_{u i}^{1} \bar{F}_{1}(\phi)$ is the rate at which a type $i$ worker with reservation wage $\phi$ will exit the unemployment pool into employment.

\subsubsection{Between Jobs and the Distribution of Earnings}

While individuals may sample wage offers from common distributions, the cross sectional distribution of wages among the employed (earnings) will differ. For example, some worker types may be more or less selective in the wages they will accept, or may 
gravitate to higher paying jobs at different rates. In what follows we denote the cumulative distribution function of sector $h$ earnings for type $i$ individuals as $G_{h i}$ with the corresponding density functions $g_{h i} \equiv G_{h i}^{\prime}$. The fraction of such workers currently employed in an hours $h$ job is denoted $m_{h i}$ and by construction we have $m_{0 i}+m_{1 i}=1-u_{i}$.

Rather than presenting flow equations for each sector separately, here it is convenient to define $q_{h i}(w)$ such that $q_{0 i}(w)=q_{i}(w)$ and $q_{1 i}(w)=w$. In steady-state, the number of type $i$ individuals who leave a sector $h$ job paying wage $q_{h i}(w)$ (either by their job being destroyed at rate $\delta_{i}$ or by gravitating to a higher value job) must exactly equal the number of individuals who accept such a job (either from the unemployment pool or from a lower value job). Hence,

$$
m_{h i} g_{h i}\left(q_{h i}(w)\right) \mathcal{D}_{e i}(w)=f_{h}\left(q_{h i}(w)\right)\left[\lambda_{u i}^{h} u_{i} A_{u i}(w)+\lambda_{e i}^{h} m_{0 i} G_{0 i}\left(q_{i}(w)\right)+\lambda_{e i}^{h} m_{1 i} G_{1 i}(w)\right]
$$

where $\mathcal{D}_{e i}(w) \equiv\left[\delta_{i}+\lambda_{e i}^{0} \bar{F}_{0}\left(q_{i}(w)\right)+\lambda_{e i}^{1} \bar{F}_{1}(w)\right]$ is the rate at which such a worker will exit their current job. Equation 6 feature a weighted distribution of full-time and parttime earnings amongst the employed, $m_{0 i} G_{0 i}\left(q_{i}(w)\right)+m_{1 i} G_{1 i}(w)$, with the individual distribution functions in this expression evaluated at wage rates that yield equal value to the worker. And while expressions for $G_{0 i}$ and $G_{1 i}$ are both individually complicated, this weighted distribution admits a considerably simpler form.

Proposition 4 The weighted distribution of earnings $m_{0 i} G_{0 i}\left(q_{i}(w)\right)+m_{1 i} G_{1 i}(w)$ may be written as:

$$
m_{0 i} G_{0 i}\left(q_{i}(w)\right)+m_{1 i} G_{1 i}(w)=\frac{A_{i}(w)-u_{i} A_{u i}(w)\left[1+\mathcal{D}_{u i}(w) / \delta_{i}\right]}{\mathcal{D}_{e i}(w) / \delta_{i}} .
$$

A proof is provided in the Supplementary Material. Thus, we are able to use this proposition to obtain expressions for the earnings densities (equation 6) in terms of the transitional parameters, wage offer distributions, and distribution of reservation wages. These may then be integrated to obtain the respective individual cumulative distribution functions and employment shares.

\subsubsection{Unemployment rate}

The steady state unemployment rate balances the flows from the unemployment pool to employment, to the job destruction induced flows from employment to unemployment. 
Proposition 5 The steady state unemployment rate of type i workers is given by:

$$
u_{i}=\frac{1}{1+\kappa_{u i}^{0}+\kappa_{u i}^{1}} A_{i}\left(\underline{\omega}_{i}\right)+\int_{\underline{\omega}_{i}}^{\bar{\omega}_{i}} \frac{d A_{i}(w)}{1+\mathcal{D}_{u i}(w) / \delta_{i}(w)}+1-A_{i}\left(\bar{\omega}_{i}\right) .
$$

where $\underline{\omega}_{i} \equiv \min \left\{\underline{w}_{1}, q_{i}^{-1}\left(\underline{w}_{0}\right)\right\}$ and $\bar{\omega}_{i} \equiv \max \left\{\bar{w}_{1}, q_{i}^{-1}\left(\bar{w}_{0}\right)\right\}$.

This proposition follows immediately by letting $\phi \rightarrow \infty$ in equation 5 . It decomposes the unemployment rate into the contribution by three (endogenously determined) groups of workers: those who accept all offers; those who accept some and reject others; and those who reject all. Note that $u_{i}$ is bounded below by $\left(1+\kappa_{u i}^{0}+\kappa_{u i}^{1}\right)^{-1}$, which is the rate that would prevail in the absence of any reservation wage heterogeneity. In contrast to the homogeneous worker model $\kappa_{e i}^{h}$ affects $u_{i}$ through two channels: the direct effect through changes in worker reservation wages and the indirect effect through its potential impact on the equilibrium wage offer distributions (described below).

\subsection{Firms}

In order to make this an equilibrium model we specify the behavior of firms. It is the profit maximizing behavior of firms, taking as given the optimal strategies of workers and other firms, that determines the equilibrium distributions of wage offers and job offer arrival rates. The type of job offer made by firms (full-time or part-time) is an exogenous technological characteristic of the firm; we therefore refer to firms as belonging to a particular hours sector. ${ }^{12}$ As in Burdett and Mortensen (1998) we assume that there is wage posting: within each hours sector employers post a single wage $w$ prior to forming matches with potential employees, who can then either accept or reject the offer. Firms also choose a level of recruiting intensity $v$ which raises their visibility in the labor market; the probability that workers draw job offers from a particular firm is proportional to this recruiting intensity.

Within each sector, firms differ in their exogenously determined productivity. The cumulative distribution of firm productivity in sector $h$ is denoted $\Gamma_{h}$ which is continuous on its support $\left[\underline{p}_{h}, \bar{p}_{h}\right]$. This productivity corresponds to the hourly flow marginal product of workers, and is independent of both the number and identity of workers. That is,

\footnotetext{
${ }^{12}$ We do however, allow the contact rate of firms to change differentially following tax reforms by inclusion of a recruiting intensity decision. Alternative approaches such as allowing firms to substitute between part-time and full-time workers (Roger and Roux, 2009), or choosing which sector to operate in (Meghir, Narita and Robin, 2010) would complicate the analysis considerably.
} 
all workers are assumed equally productive at a given firm regardless of their observed or unobserved type. The flow cost of recruiting effort may also differ across firms. We denote this as $c_{h}(v ; p)$ with this function strictly convex in $v$ and with $c_{h}(0 ; p)=0$.

\subsubsection{Firm Size}

The number of workers of a given observable type $i$ that a sector $h$ firm employs at wage $w$ and recruiting intensity $v$ is denoted $l_{h i}(w, v)$. Since firms may potentially contact workers of all types, total employment at such a firm is given by $L_{h}(w, v)=\sum_{i} n_{i} l_{h i}(w, v)$. In steady state, sector $h$ employment $l_{h i}(w, v)$ solves the flow equation:

$$
l_{h i}\left(q_{h i}(w), v\right) \mathcal{D}_{e i}(w)=\frac{v}{V_{h}}\left[\lambda_{u i}^{h} u_{i} A_{u i}(w)+\lambda_{e i}^{h} m_{0 i} G_{0 i}\left(q_{i}(w)\right)+\lambda_{e i}^{h} m_{1 i} G_{1 i}(w)\right],
$$

which balance the number of workers who enter and exit employment at a given firm. Note that $l_{h i}(w, v)$ is non-decreasing in $w$. This is because firms which pay higher wages attract more workers from both the unemployment pool (the mechanism in Albrecht and Axell, 1984) and lower value firms (the mechanism in Burdett and Mortensen, 1998). In these flow equations $V_{h}$ denotes the aggregate recruiting intensity in hours sector $h$ :

$$
V_{h}=\int_{\underline{p}}^{\bar{p}} v_{h}(p) d \Gamma_{h}(p)
$$

and with $v_{h}(p)$ denoting the recruiting policy of a sector $h$ productivity $p$ firm. Given that the recruiting intensity $v$ enters the RHS of equation 9 multiplicatively, it is convenient in what follows to write $l_{h i}(w, v)=\bar{l}_{h i}(w) v / V_{h}$, and similarly define $\bar{L}_{h}(w)=$ $\sum_{i} n_{i} \bar{l}_{h i}(w)$. Substituting equation 7 into equation 9 we may eliminate the weighted cross-sectional earnings distributions and establish the following result.

Proposition 6 Steady state employment levels in sector $h$ for given wage $w$ and recruiting intensity $v$ are given by $l_{h i}(w, v)=\bar{l}_{h i}(w) \cdot v / V_{h}$ with:

$$
\bar{l}_{h i}\left(q_{h i}(w)\right)=\frac{\kappa_{e i}^{h} A_{i}(w)+\left[\kappa_{u i}^{h} \mathcal{D}_{e i}(w) / \delta_{i}-\kappa_{e i}^{h}\left(1+\mathcal{D}_{u i}(w) / \delta_{i}\right)\right] u_{i} A_{u i}(w)}{\left(\mathcal{D}_{e i}(w) / \delta_{i}\right)^{2}} .
$$

In contrast to models without reservation wage heterogeneity, the absence of on-thejob search $\left(\kappa_{e i}^{h}=0\right)$ does not imply that employment is uniformly distributed across firms when matching is random. This is intuitive because low wage firms are only 
able to attract low reservation wage workers (it is straightforward to show that $\bar{l}_{h i}(w)$ is proportional to $A_{u i}(w)$ in this case). More generally, firm size depends upon a weighted distribution of reservation wages amongst employed and unemployed workers, with the weights a function of job offer arrival rates and the distributions of wage offers.

\subsubsection{Firm Profits}

Each firm chooses its wage policy $w_{h}(p)$ and recruiting policy $v_{h}(p)$ to maximize its steady state profit flow, ${ }^{13}$ taking the arrival rate of job offers, together with the behavior of other firms (both part-time and full-time) and workers as given. Hence:

$$
\left\{w_{h}(p), v_{h}(p)\right\}=\underset{(w, v)}{\arg \max } \bar{\pi}_{h}(w ; p) \frac{v}{V_{h}}-c_{h}(v ; p)
$$

where $\bar{\pi}_{h}(w ; p)=(p-w) h \cdot \bar{L}_{h}(w)$ is the expected profit flow per unit intensity. The optimal recruiting policy $v_{h}(p)$ equates the marginal cost of increasing recruiting effort to the marginal expected profit flow. That is:

$$
\left.\frac{\partial c_{h}(v ; p)}{\partial v}\right|_{v=v_{h}(p)}=\frac{\bar{\pi}_{h}\left(w_{h}(p) ; p\right)}{V_{h}} .
$$

Maximized expected profit flow per unit intensity is given by $\bar{\pi}_{h}(p)=\bar{\pi}_{h}\left(w_{h}(p) ; p\right)=$ $\left(p-w_{h}(p)\right) h \cdot \bar{L}_{h}\left(w_{h}(p)\right)$ so that $\bar{\pi}_{h}^{\prime}(p)=\bar{L}_{h}\left(w_{h}(p)\right)$ by the Envelope Theorem. Since $\bar{L}_{h}(w)$ is increasing in $w$, and $w_{h}(p)$ is increasing in $p$, it follows that the maximized expected profit flow per unit intensity is a convex function of $p$. Rather than working directly with the first order conditions for the optimal wage policy of firms, we write firms' expected profit flow per unit intensity as:

$$
\bar{\pi}_{h}(p)=\bar{\pi}_{h}^{*}\left(\underline{p}_{h}\right)+h \int_{\underline{p}_{h}}^{p} \bar{L}_{h}\left(w_{h}(y)\right) d y
$$

where $\bar{\pi}_{h}^{*}\left(\underline{p}_{h}\right)=\max _{w}\left(\underline{p}_{h}-w\right) \bar{L}_{h}(w)$ are the maximized profits for the least productive sector $h$ firm. Setting equation $1_{4}$ equal to $\left(p-w_{h}(p)\right) h \bar{L}_{h}(p)$ we obtain the following expression for the wage policy function:

\footnotetext{
${ }^{13}$ This is the standard assumption in the wage-posting literature. It assumes that firms have a zero rate of time preference. See Mortensen (2000) for a discussion.
} 
Proposition 7 The optimal wage policy of firms $w_{h}(p)$ satisfies the following equation:

$$
w_{h}(p)=p-\left[\pi_{h}^{*}\left(\underline{p}_{h}\right)+h \int_{\underline{p}_{h}}^{p} \bar{L}_{h}\left(w_{h}(y)\right) \mathrm{d} y\right] \times \frac{1}{h \bar{L}_{h}\left(w_{h}(p)\right)}
$$

which is a form that we exploit when we numerically solve for the equilibrium of our model (see the Supplementary Material for details).

\subsection{Matching Technology and Equilibrium}

In order to close the model we endogenize the arrival rate of job offers by complementing it with aggregate matching functions (see Mortensen, 2000). The total flow of matches in each hours sector $h$ is denoted $M_{h}\left(V_{h}, S_{h}\right)$; it depends on the total recruiting intensity $V_{h}$ and the total intensity adjusted search effort of workers $S_{h}$ :

$$
S_{h}=\sum_{i} n_{i}\left[s_{u i}^{h} u_{i}+s_{e i}^{h}\left(1-u_{i}\right)\right]
$$

where $s_{j i}^{h}$ denotes the exogenous search effort of type $i$ workers that is directed to sector $h$ when in state $j \in\{u, e\}$. By assumption, the matching function $M_{h}$ is increasing in both its arguments, concave, and linearly homogeneous. The job offer arrival rates for each worker type are then related to the flows of matches according to:

$$
\lambda_{j i}^{h}=s_{j i}^{h} \cdot M_{h}\left(V_{h}, S_{h}\right) / S_{h}
$$

The market equilibrium of the economy is now defined in Definition 1.

Definition 1 A market equilibrium is defined by $\left\{F_{0}, F_{1}, v_{0}, v_{1}\right\}$ such that simultaneously:

1. The arrival rates of job offers $\left\{\lambda_{u i}^{0}, \lambda_{e i}^{0}, \lambda_{u i}^{1}, \lambda_{e i}^{1}\right\}_{i \leq I}$ are given by equation 17.

2. The distribution of wage offers in the economy is:

$$
F_{0}\left(w_{0}(p)\right)=\int_{\underline{p}_{0}}^{p} \frac{v_{0}(p) d \Gamma_{0}(p)}{V_{0}} \text { and } F_{1}\left(w_{1}(p)\right)=\int_{\underline{p}_{1}}^{p} \frac{v_{1}(p) d \Gamma_{1}(p)}{V_{1}}
$$

with $V_{h}$ as defined in equation 10. 
3. The strategy of each type $i$ worker with leisure flow $b$ is to accept any full-time (part-time) wage greater than $\phi_{i}(b)$ (respectively, $\phi_{i}\left(q_{i}(b)\right)$ ) when unemployed; when employed in the full-time (part-time) sector at wage $w$ (respectively, $q_{i}(w)$ ), the strategy is to accept any full-time wage strictly greater than $w$ and any part-time wage strictly greater than $q_{i}(w)$.

4. The strategy of each sector $h$ productivity $p$ firm is to choose a recruiting intensity $v_{h}(p)$ and wage $w_{h}(p)$ that maximizes profits given the job offer arrival rates, strategies of other firms' and workers', as in equation 12.

\section{Estimation}

This section discusses the structural estimation of our model using longitudinal survey data. We first derive the likelihood function, and proceed to discuss identification and the estimation procedure. We then discuss our application of the UK tax and transfer system and the data used in estimation. Results are presented in Section 3.6.

\subsection{Likelihood Function}

We derive the likelihood contribution for individuals in different initial labor market positions, and with different observed transitions. Note that we do not use any information beyond the first observed transition, and that the steady state distributions of earnings and employment/unemployment shares have been used to determine the initial conditions. The presentation closely follows that of Bontemps, Robin and van den Berg (1999). In what follows elapsed and residual durations are given by:

$$
\begin{aligned}
t_{u b} & =\text { elapsed unemployment duration } \\
t_{u f} & =\text { residual unemployment duration } \\
d_{u b} & =1 \text { if unemployment duration left-censored, otherwise } 0 \\
d_{u f} & =1 \text { if unemployment duration right-censored, otherwise } 0 \\
t_{e b} & =\text { elapsed employment duration } \\
t_{e f} & =\text { residual employment duration } \\
d_{e b} & =1 \text { if employment duration left-censored, otherwise } 0 \\
d_{e f} & =1 \text { if employment duration right-censored, otherwise } 0
\end{aligned}
$$


while earned and accepted wages are denoted as follows:

$$
\begin{aligned}
w_{u} & =\text { full-time wage accepted by unemployed individuals } \\
q_{i}\left(w_{u}\right) & =\text { part-time wage accepted by unemployed individuals } \\
d_{u} & =1 \text { if wage accepted by unemployed is unobserved, otherwise } 0 \\
w_{e} & =\text { full-time wage of employees at date of first interview } \\
q_{i}\left(w_{e}\right) & =\text { part-time wage of employees at date of first interview } \\
d_{e} & =1 \text { if wage of employees is unobserved, otherwise } 0 .
\end{aligned}
$$

Current employment is indexed by:

$$
\begin{aligned}
& h_{e}^{0}=1 \text { if employed work in the part-time sector, otherwise } 0 \\
& h_{e}^{1}=1 \text { if employed work in the full-time sector, otherwise } 0,
\end{aligned}
$$

and initial transitions are indexed by:

$$
\begin{aligned}
& v_{u}^{0}=1 \text { if unemployed accept a part-time job, otherwise } 0 \\
& v_{u}^{1}=1 \text { if unemployed accept a full-time job, otherwise } 0 \\
& v_{e}^{0}=1 \text { if employed accept a part-time job, otherwise } 0 \\
& v_{e}^{1}=1 \text { if employed accept a full-time job, otherwise } 0 .
\end{aligned}
$$

\subsubsection{Unemployed Workers}

The exact form that the likelihood contribution for unemployed workers of type $i$ will take will depend upon whether unemployment durations are subject to any censoring and the type of wage offer accepted, if observed. If unemployed workers are observed to exit unemployment to a full-time job paying $w_{u}$ or a part-time job paying $q_{i}\left(w_{u}\right)$, then we must have both $d_{u}=0$ and $d_{u f}=0$. The likelihood contribution is given by:

$$
\begin{aligned}
\int_{-\infty}^{w_{u}} \mathcal{D}_{u i}(\phi)^{2-d_{u b}} \exp \left[-\mathcal{D}_{u i}(\phi)\left(t_{u b}+\right.\right. & \left.\left.t_{u f}\right)\right] \\
& \times \frac{\left(\lambda_{u i}^{0} f_{0}\left(q_{i}\left(w_{u}\right)\right)\right)^{v_{u}^{0}}\left(\lambda_{u i}^{1} f_{1}\left(w_{u}\right)\right)^{v_{u}^{1}}}{\mathcal{D}_{u i}(\phi)} \frac{d A_{i}(\phi)}{1+\mathcal{D}_{u i}(\phi) / \delta_{i}},
\end{aligned}
$$


where we have integrated over the distribution of possible reservations wages given the observed accepted wage rate using equation 5 .

If we do not observe a wage accepted by the unemployed $\left(d_{u}=1\right)$, but we nonetheless have $d_{u b}+d_{u f}<2$, then it still must be the case that the full-time reservation wage of such an individual is no greater than $\bar{\omega}_{i}$. The likelihood contribution is therefore:

$$
\begin{aligned}
\left.\int_{-\infty}^{\bar{\omega}_{i}} \mathcal{D}_{u i}(\phi)^{2-d_{u b}-d_{u f} \exp \left[-\mathcal{D}_{u i}(\phi)\right.}\left(t_{u b}+t_{u f}\right)\right] \\
\times\left[\frac{\left(\lambda_{u i}^{0} \bar{F}_{0}\left(q_{i}(\phi)\right)\right)^{v_{u}^{0}}\left(\lambda_{u i}^{1} \bar{F}_{1}(\phi)\right)^{v_{u}^{1}}}{\mathcal{D}_{u i}(\phi)}\right]^{1-d_{u f}} \frac{d A_{i}(\phi)}{1+\mathcal{D}_{u i}(\phi) / \delta_{i}} .
\end{aligned}
$$

Finally, if we have both $d_{u}=1$ and $d_{u b}+d_{u f}=2$, then the individual is never observed in the employment state so we must also consider the probability that such an individual has a reservation wage that is greater than $\bar{\omega}_{i}$. The likelihood contribution then becomes:

$$
\int_{-\infty}^{\bar{\omega}_{i}} \exp \left[-\mathcal{D}_{u i}(\phi)\left(t_{u b}+t_{u f}\right)\right] \frac{d A_{i}(\phi)}{1+\mathcal{D}_{u i}(\phi) / \delta_{i}}+\left[1-A_{i}\left(\bar{\omega}_{i}\right)\right]
$$

\subsubsection{Employed Workers}

The likelihood contribution of a type $i$ individual working full-time (part-time) at wage $w_{e}\left(q_{i}\left(w_{e}\right)\right)$ is given by:

$$
\begin{aligned}
\left\{m_{0 i} g_{0 i}\left(q_{i}\left(w_{e}\right)\right)\right\}^{h_{e}^{0}}\left\{m_{1 i} g_{1 i}\left(w_{e}\right)\right\}^{h_{e}^{1}} & \mathcal{D}_{e i}\left(w_{e}\right)^{2-d_{e b}-d_{e f}} \exp \left[-\mathcal{D}_{e i}\left(w_{e}\right)\left(t_{e b}+t_{e f}\right)\right] \\
& \times\left[\frac{\delta_{i}^{1-v_{e}^{0}-v_{e}^{1}}\left(\lambda_{e i}^{0} \bar{F}_{0}\left(q_{i}\left(w_{e}\right)\right)\right)^{v_{e}^{0}}\left(\lambda_{e i}^{1} \bar{F}_{1}\left(w_{e}\right)\right)^{v_{e}^{1}}}{\mathcal{D}_{e i}\left(w_{e}\right)}\right]^{1-d_{e f}} .
\end{aligned}
$$

The likelihood function takes the same form for an employed worker whose wage is unobserved $\left(d_{e}=1\right)$, except that we now integrate the above likelihood contribution over the support of wages.

A common difficulty with the structural estimation of wage posting models is that they do not permit job-to-job transitions associated with wage cuts. In the context of the model developed here, wage cuts may be permitted if an individual changes hours sectors, but reductions in the value of jobs are not. ${ }^{14}$ In the likelihood contribution for

\footnotetext{
${ }^{14}$ The model could potentially be extended to allow for job-to-job transitions associated with lower values by introducing a reallocation shock as in Jolivet, Postel-Vinay and Robin (2006). These shocks are draws
} 
employed workers (presented above) note that we do not use any information on the wage accepted following a job-to-job transition. This partial information approach has been adopted in a number of other empirical applications of wage posting models (see for example, Kiefer and Neumann, 1993, and Bontemps, Robin and van den Berg, 1999). An additional complication here is that the transition between hours sectors may also be a zero probability event in some regions of the parameter space for some individuals. While there are a number of ways of potentially addressing this issue, we adopt a simple approach by assuming that there is some small probability that the hours sector following a job-to-job transition is observed with error. ${ }^{15}$

\subsection{Identification}

To understand the separate identification of the wage offer and reservation wage distributions, it is useful to first consider a special case of our model in the absence of hours sectors, a tax system, and demographic heterogeneity, and where the distribution of leisure flows collapses to a degenerate distribution (i.e. workers are homogeneous). This is the model analyzed in Bontemps, Robin and van den Berg (2000). Conditional on transitional parameters, identification of the wage offer distribution follows directly from a steady state relationship between the wage offer and earnings distributions. Moreover, in such a setting all job offers will be accepted by all unemployed workers so that the accepted wage distribution will coincide with the wage offer distribution. This special case of our more general model is therefore over-identified.

Regardless of its source, once we allow for heterogeneity in the reservation wage of unemployed workers the distribution of accepted wages will no longer equal the wage offer distribution. This is because workers are selective in the wages that they are willing to accept, so that the distribution of accepted wages (which will stochastically dominate the wage offer distribution) will depend upon two distributions. We are still able to establish non-parametric identification in this case because we observe as many

from the wage offer distributions for which the only alternative to acceptance is to become unemployed. The presence of reservation wage heterogeneity complicates the analysis as some individuals may wish to exercise the unemployment option upon receiving such a shock.

${ }^{15}$ Alternatives approaches such as modeling the hours disutility as unobserved heterogeneity, or incorporating the measurement error through wages (as in van den Berg and Ridder, 1998) would complicate the analysis considerably. In all the estimation results we fix this transitional measurement error probability to $5 \%$, although our main results are not sensitive to this particular choice. We also note that conditional on our maximum likelihood estimates, no transition across sectors observed in our data would actually have zero probability. See Bound et al. (1994) for US evidence on measurement error in wages and hours. 
distributions (starting wages and cross-sectional earnings) as distributions that we wish to recover. If we observe further distributions, such as the distribution of wages that the employed receive in their next job, then we once again will have over-identification. ${ }^{16}$ These ideas are presented more formally in the Supplementary Material, and are closely related to the estimation procedure that we now present.

\subsection{Three Step Estimation Procedure}

The likelihood function depends directly upon the part-time and full-time wage offer distributions, which themselves depend upon the exogenous distributions of firm productivity and the other structural parameters of the model. Moreover, the conditional earnings distributions, distribution of reservation wages, and the unemployment and employment shares, are all complicated functions of these distributions and parameters. Rather than attempting to solve the full model at each stage of the estimation, we instead estimate the model using a three step procedure that is an extension of that proposed in Bontemps, Robin and van den Berg (1999, 2000). Specifically:

1. We estimate $\left\{\underline{w}_{0}, \bar{w}_{0}\right\}$ as the sample minimum and maximum values of $w_{e}$ amongst part-time jobs and $\left\{\underline{w}_{1}, \bar{w}_{1}\right\}$ as the sample minimum and maximum values of $w_{e}$ amongst full-time jobs. None of these estimates condition upon worker type. We then calculate estimates of the unconditional earnings densities in each sector using non-parametric techniques. We denote these estimated densities as $\hat{g}_{0}$ and $\hat{g}_{1}{ }^{17}$

2. We assume a parametric form for the distribution of unobserved leisure flows $H_{i}$ with a finite parameter vector $\left\{\boldsymbol{\theta}_{H_{i}}\right\}_{i \leq I}$. Since workers are assumed to sample wages from the same wage offer distributions $F_{0}$ and $F_{1}$ regardless of their demographic type $i$, we weight equation 6 by $n_{i}$ and sum across types to obtain appropriately averaged equations of the form:

$$
f_{h}(w)=\frac{\sum_{i} n_{i} m_{h i} g_{h i}(w)}{\sum_{i} n_{i} \bar{l}_{h i}(w)}
$$

for $h \in\{0,1\}$. We replace the numerator of equation 19 by $m_{h} \hat{g}_{h}(w)$, where $m_{h}=\sum_{i} n_{i} m_{h i}$. To recover the part-time and full-time offer distributions that induce

\footnotetext{
${ }^{16}$ This is related to the approach taken by Barlevy (2008) and Barlevy and Nagaraja (2006) who using record-value theory demonstrate identification of the wage offer distribution by tracking the wage growth of workers as a function of past mobility.

${ }^{17}$ In our empirical application we use Gaussian kernel estimators with a bandwidth of 0.5 .
} 
our estimates of the unconditional empirical earnings distributions, we provide an initial guess of $f_{0}$ and $f_{1}$ and then repeatedly (and simultaneously) iterate on this equation for both $h_{0}$ and $h_{1}$, exploiting the conditional linearity seen above. At each iteration step we scale the densities by a normalization factor to ensure that we have proper distribution functions, and then verify that these normalization factors converge to 1 . Conditional on the transitional parameters and distributions of leisure flows, we obtain consistent estimates of the offer distributions and their densities, which we respectively denote $\hat{F}_{h}$ and $\hat{f}_{h}$. These estimates are then substituted into the likelihood function. They are also used to calculate the conditional employment shares and earnings densities: $u_{i}\left(\hat{F}_{0}, \hat{F}_{1}\right), m_{h i}\left(\hat{F}_{0}, \hat{F}_{1}\right)$, and $g_{h i}\left(\cdot ; \hat{F}_{0}, \hat{F}_{1}\right)$.

3. Given a parametric form for the matching functions $M_{h}\left(V_{h}, S_{h}\right)$ and the recruiting cost functions $c_{h}(v ; p)$ (we discuss our calibration of these in Section 4 ), we obtain the implied distribution of firm productivity and recruiting efforts by rewriting the first order conditions from the firms' maximization problem in each sector $h$ as:

$$
p=w_{h}^{-1}(w)=w+\bar{L}_{h}(w) / \bar{L}_{h}^{\prime}(w),
$$

and then using equations 13 and 17 , together with the relationship $F_{h}\left(w_{h}(p)\right)=$ $\int_{\underline{p}_{h}}^{p} v_{h}(p) / V_{h} d \Gamma_{h}(p)$ from Definition 1. If the discount rate $\rho_{i}$ is known, then the distribution of leisure flows $H_{i}$ can then be recovered using equation 2.

We construct confidence intervals by bootstrapping the three stage estimation procedure. The advantages of this multi step procedure versus a completely parametric approach (whereby we specify the underlying distribution of firm productivity and then solve for the equilibrium of the model) are essentially threefold. Firstly, it is considerably easier to perform this numerical inversion than it is to solve the full model at every evaluation of the likelihood function. Second, it permits greater flexibility than simple parametric forms for the productivity distribution. Thirdly, since this semi-parametric estimation procedure does not require assumptions regarding the determination of $F_{h}$, these estimates and those of the transitional parameters are valid under a range of possible models. Conversely, the main disadvantage of this approach compared to a completely parametric specification, is that it does not guarantee a monotonically increasing relationship between wages and productivity (in which case the empirical distribution of wages can not be an equilibrium outcome from our model), and in general it may not 
be possible to constrain the structural parameters to achieve such monotonicity. ${ }^{18}$

\subsection{Applying the UK Tax and Transfer System}

Our empirical application seeks to accurately represent the main features of the UK tax and transfer system so that we may consider the impact of a series of tax reforms. We do not attempt to describe the full UK system here, but the interested reader may consult Adam and Browne (2009) and Jin, Levell and Phillips (2010) for recent surveys. The underlying tax and transfer schedules are calculated prior to estimation using FORTAX (Shephard, 2009), and reflect the complex interactions between the tax and transfer system, varying accurately with earnings, hours of work and demographic characteristics. ${ }^{19}$

To economize on the number of groups that we need to consider (and structural parameters to estimate), we make a number of further assumptions regarding the set of demographic types. Specifically, we do not allow taxes and transfers to vary by the age of the claimant or by the age of any children. Taxes and transfers are calculated as if the claimant were at least 25 years old, and as if any children are aged 10. Families with more than two children are treated as if there were only two children. Since some benefits have asset tests, we also assume that no families in our sample are affected by them. All families are assigned average band C council tax (a local property based tax). ${ }^{20}$

The model developed in Section 2 assumed the presence of a single economic decision maker. This presents difficulties for our empirical application because transfers and in-work tax credits are assessed on family income in the UK. A complete treatment of couples is beyond the scope of this paper (see Guler, Guvenen and Violante, 2009, for a theoretical characterization of the reservation wage strategy of couples with income pooling). Rather than providing a detailed characterization of the household decision making process, we take an admittedly limited approach by conditioning upon the current employment status and (discretized) earnings of the individuals' partner. We then

\footnotetext{
${ }^{18}$ In principle we could estimate the model using data from both before and after the reforms, treating each as a different steady state from the model. This would require solving the full model, as the model imposes structure on the relationship between the distributions of wage offers and arrival rates across steady states under different tax systems. It is also complicated by the non-tax changes over this period.

${ }^{19} \mathrm{~A}$ potentially important benefit that we do not model is housing benefit, a transfer given to low income families to assist with housing rent. The Labour Force Survey data used in our empirical application does not contain data on rents. Since tax credit income results in housing benefit entitlement being withdrawn, families in receipt of housing benefit would gain less from WFTC than otherwise equivalent families. This omission means that we are likely to overstate the initial labor supply response for some types.

${ }^{20} \mathrm{Band} \mathrm{C}$ is the most common band; the Labour Force Survey data does not report banding information.
} 
subsume partner earnings in the tax schedule, but allow this tax schedule to accurately vary with the earnings of both individuals. In our empirical application we discretize the empirical distribution of partner earnings (conditional on gender and the presence and number of children) into ten groups, including non-employment (zero earnings); actual partner earnings are then replaced with those observed at either the $10^{\text {th }}, 20^{\text {th }}, \ldots$, or $90^{\text {th }}$ percentile point of the relevant empirical distribution. When the earnings of an individual's partner is unobserved, we integrate the respective likelihood contribution of individuals (see Section 3.1) over the corresponding distribution of partner earnings.

The above categorization requires that we consider $I=64$ different worker types. Conditional on hours of work, the resultant tax schedules for each of these groups as a function of the wage rate will be a piecewise linear function, with possible discontinuities. We first remove these discontinuities by appropriately modifying parameters of the tax and transfer system. The modified marginal tax rate schedule for fixed hours is then replaced by a differentiable function using the method proposed by MaCurdy, Green and Paarsch (1990), which essentially smoothes the tax schedule in the neighborhood of any marginal rate changes. Details are provided in the Supplementary Material.

\subsection{Data}

We estimate our model using a sub-sample of the UK Labour Force Survey (LFS). The LFS is a quarterly survey of around 60,00o households in Great Britain, with these households followed for five successive quarters or "waves". When individuals first enter the survey they are in wave one, so that in any given quarter, there are roughly equal proportions of individuals in each interview wave. This rolling panel structure means that there is approximately an $80 \%$ overlap in the samples for successive quarters. ${ }^{21}$

The LFS provides us with very rich information concerning the respondents labor market status. Crucially, we observe employment status and spell durations, together with hours and earnings information (in the first and fifth waves since 1997) for workers. Our pre-reform estimation is performed using data before WFTC was introduced or announced. We follow individuals who are observed in the first quarter of 1997 until (at the latest) the first quarter of 1998. We calculate incomes and construct the likelihood function as if individuals always faced the April 1997 system during this period so that

\footnotetext{
${ }^{21}$ The short panel dimension of the LFS is of some concern as relatively few transitions are observed. While alternative panel data sets, such as the British Household Panel Survey, provide a more extensive panel, the sample size is much smaller.
} 
the environment is stationary. While we may observe long elapsed spell durations, we nonetheless impose left censoring for durations greater than 24 months as it is difficult to justify the assumption that they were generated from the same steady state.

We classify individuals as being employed if they have a job, and non-employed if they do not. Since we do not distinguish between the states of unemployment and non-participation, this definition of non-employment is broader than the standard ILO unemployment definition. Amongst the employed, women who report working less than 30 hours per week are classified as part-time workers, while those working at least 30 hours per week are classified as full-time workers. We set $h_{0}=20$ and $h_{1}=40$, which correspond well to the respective conditional averages. Empirically, very few men work part-time, so we treat all male workers as working full-time and set $C_{i}^{1}=0$. In both cases, we calculate gross wages using reported hours of work, but then proceed to calculate incomes as if they were working at the relevant discrete hours point.

Individuals who are aged below 21 or above 50 are excluded from our sample, as are individuals in full-time education. We also exclude individuals when any adult family member is either self-employed or long-term sick/disabled. Given the assumption that workers are equally productive at a given firm, we additionally restrict our sample to those individuals whose highest qualification is O-level (or equivalent) or below, and assume that any higher educated individuals operate in a separate labor market. After sample selection we have roughly 24,000 observations. Summary statistics are presented in the Supplementary Material.

While the tax and transfer schedules may vary with each observable type, we only allow the structural parameters of the model to depend on a subset of demographic types. For couples we do not allow the parameters to vary with the earnings and labor market status of their partner; for parents we do not allow them to vary with the number of their children. The distribution of work opportunity costs $H_{i}$ is assumed to be Normally distributed, with mean $\mu_{i}$ and standard deviation $\sigma_{i}{ }^{22}$

\subsection{Estimation Results and Model Fit}

Given our parameter estimates (Table 1 ), the implied wage policy functions $w_{0}(p)$ and $w_{1}(p)$ that are obtained from the first order conditions to the firms' profit maximization problem (equation 20) are found to be monotonically increasing in $p$ so that the esti-

${ }^{22}$ The leisure flow distribution was poorly identified for single women. In the results presented we have restricted the distribution of leisure flows to be the same for married and single women without children. 
Table 1: Maximum Likelihood Structural Parameter Estimates

\begin{tabular}{|c|c|c|c|c|c|c|c|c|}
\hline & $1 / \delta_{i}$ & $1 / \lambda_{u i}^{0}$ & $1 / \lambda_{u i}^{1}$ & $1 / \lambda_{e i}^{0}$ & $1 / \lambda_{e i}^{1}$ & $\mu_{i}$ & $\sigma_{i}$ & $C_{i}^{1}$ \\
\hline single men & $\begin{array}{c}90 \cdot 1 \\
{[85 \cdot 0,97 \cdot 1]}\end{array}$ & - & $\begin{array}{c}13.6 \\
{[11.0,16.7]}\end{array}$ & - & $\begin{array}{c}21.5 \\
{[18.2,25.9]}\end{array}$ & $\begin{array}{c}6.5 \\
{[-17 \cdot 9,22.8]}\end{array}$ & $\begin{array}{c}64 \cdot 4 \\
{[43 \cdot 9,89 \cdot 7]}\end{array}$ & - \\
\hline married men, no kids & $\begin{array}{c}171.4 \\
{[154 \cdot 5,188.1]}\end{array}$ & - & $\begin{array}{c}4 \cdot 4 \\
{[3 \cdot 2,6.0]}\end{array}$ & - & $\begin{array}{c}16.1 \\
{[13 \cdot 7,19.5]}\end{array}$ & $\begin{array}{c}-80.1 \\
{[-149.1,-34.1]}\end{array}$ & $\begin{array}{c}111.5 \\
{[81.7,155.1]}\end{array}$ & - \\
\hline married men, kids & $\begin{array}{c}184.6 \\
{[171.6,198.8]}\end{array}$ & - & $\begin{array}{c}11.4 \\
{[9.0,13.8]}\end{array}$ & - & $\begin{array}{c}14.5 \\
{[12.2,17.6]}\end{array}$ & $\begin{array}{c}9.9 \\
{[-13 \cdot 5,27 \cdot 5]}\end{array}$ & $\begin{array}{c}55.2 \\
{[39.8,73.6]}\end{array}$ & - \\
\hline single women & $\begin{array}{c}127.9 \\
{[117.0,139.7]}\end{array}$ & $\begin{array}{c}20.2 \\
{[15 \cdot 7,25 \cdot 7]}\end{array}$ & $\begin{array}{c}19 \cdot 9 \\
{[14 \cdot 5,27.1]}\end{array}$ & $\begin{array}{c}115.1 \\
{[64 \cdot 3,282.1]}\end{array}$ & $\begin{array}{c}31.5 \\
{[26.7,38.5]}\end{array}$ & $\begin{array}{c}-73 \cdot 6 \\
{[-112 \cdot 3,-45 \cdot 4]}\end{array}$ & $\begin{array}{c}107.6 \\
{[84.3,139.2]}\end{array}$ & $\begin{array}{c}18.9 \\
{[8.8,27.9]}\end{array}$ \\
\hline single parents & $\begin{array}{c}69.9 \\
{[65 \cdot 2,76.4]}\end{array}$ & $\begin{array}{c}56 \cdot 4 \\
{[43 \cdot 9,93 \cdot 3]}\end{array}$ & $\begin{array}{c}439.6 \\
{[263.6,1055 \cdot 4]}\end{array}$ & $\begin{array}{c}75 \cdot 3 \\
{[55 \cdot 7,102.3]}\end{array}$ & $\begin{array}{c}36.9 \\
{[29.6,46.0]}\end{array}$ & $\begin{array}{c}43.0 \\
{[29.8,48.9]}\end{array}$ & $\begin{array}{c}30.9 \\
{[7.8,64 \cdot 1]}\end{array}$ & $\begin{array}{c}36.1 \\
{[32.9,39 \cdot 3]}\end{array}$ \\
\hline married women, no kids & $\begin{array}{c}157.0 \\
{[144.8,168.8]}\end{array}$ & $\begin{array}{c}22.9 \\
{[16.7,30.3]}\end{array}$ & $\begin{array}{c}16.6 \\
{[12.2,23.0]}\end{array}$ & $\begin{array}{c}109.8 \\
{[84.0,152.7]}\end{array}$ & $\begin{array}{c}51.9 \\
{[43 \cdot 4,65.9]}\end{array}$ & $\begin{array}{c}-73 \cdot 6 \\
{[-112 \cdot 3,-45 \cdot 4]}\end{array}$ & $\begin{array}{c}107.6 \\
{[84 \cdot 3,139.2]}\end{array}$ & $\begin{array}{c}51 \cdot 7 \\
{[45 \cdot 0,58 \cdot 3]}\end{array}$ \\
\hline married women, kids & $\begin{array}{c}102.6 \\
{[98.0,108.1]}\end{array}$ & $\begin{array}{c}24.1 \\
{[20.3,28.8]}\end{array}$ & $\begin{array}{c}127.5 \\
{[90.6,189.8]}\end{array}$ & $\begin{array}{c}35.2 \\
{[30.9,40.8]}\end{array}$ & $\begin{array}{c}84.2 \\
{[69.0,103.5]}\end{array}$ & $\begin{array}{c}32.5 \\
{[27 \cdot 2,36.5]}\end{array}$ & $\begin{array}{c}48.5 \\
{[43.8,54.5]}\end{array}$ & $\begin{array}{c}4^{2.1} \\
{[34.0,50.5]}\end{array}$ \\
\hline
\end{tabular}

Notes: All durations are monthly. Incomes are measured in pounds per week in April 1997 prices. The distribution of work opportunity costs $H_{i}$ is assumed to be Normal, with mean $\mu_{i}$ and variance $\sigma_{i}^{2}$. The $5^{\text {th }}$ and $95^{\text {th }}$ percentiles of the bootstrap distribution of parameter estimates are presented in brackets, and are calculated using 500 bootstrap replications. 
mated empirical distribution of wages can be an equilibrium outcome from our model. That is, the theoretical model is not rejected by the data. ${ }^{23}$ These wage policy functions are presented in Figure 2a. The first notable feature evident in this figure is that the wage policy functions become flat as productivity increases so that high productivity firms have a high degree of monopsony power. Second, the extent of monopsony power is lower for part-time firms at high wages. When wages are high, the monetary disutility of work becomes small relative to earnings so that part-time firms must offer higher wages if they are to attract workers from full-time jobs. The underlying distributions of firm productivity are shown in Figure 2b, with both part-time and full-time distributions highly skewed to the right. The associated estimated wage offer distributions are presented in Figure 2c, which shows that there is a relatively higher concentration of low wage offers among part-time firms. Finally, the unconditional distribution of wage earnings that these distributions induce is shown in Figure $2 \mathrm{~d}$.

The estimates suggest that there is considerable heterogeneity across groups. The job destruction rate (which is relatively precisely estimated across all groups) is highest for single parents $\left(\hat{\delta}_{i}=0.014\right)$ with this estimate implying that jobs are exogenously destroyed on average every 70 months $(=1 / 0.014)$. The destruction rates are lowest for married men and married women without dependent children, where they are estimated to be around two and a half times as small. The arrival rates of job offers also varies considerably across groups. Job offers arrive most frequently for men: for unemployed married men without children we obtain $\hat{\lambda}_{u i}^{1}=0.226$, while for single men and married men without children we obtain lower estimates (0.074 and 0.088 respectively). Of course, not all these job offers will be acceptable to all workers. The estimated total job offer arrival rates $\hat{\lambda}_{u i}^{0}+\hat{\lambda}_{u i}^{1}$ for unemployed childless women is broadly similar to the values of $\hat{\lambda}_{u i}^{1}$ for men. However, for unemployed single parents and married women with children we obtain much lower job offer arrival rates (particularly for full-time jobs).

For the majority of groups, the estimated job offer arrival rate when employed is less than that when unemployed, although in some cases the estimated parameters are very similar in value. For single men we obtain the relative arrival rate ratio $\hat{\lambda}_{u i}^{1} / \hat{\lambda}_{e i}^{1}=$ 1.6, while this ratio is somewhat higher for married men without children $(=3.6)$ and slightly lower for married men with children (=1.3). In this latter case we can not reject

${ }^{23}$ Monotonicity is violated for a small proportion of the bootstrap samples. In order to construct bootstrap confidence intervals for the policy responses we therefore first apply a rearrangement procedure (see Chernozhukov, Fernandez-Val and Galichon, 2007). These violations are not a large concern as they typically occur for very high productivity full-time firms where the density becomes very low. 


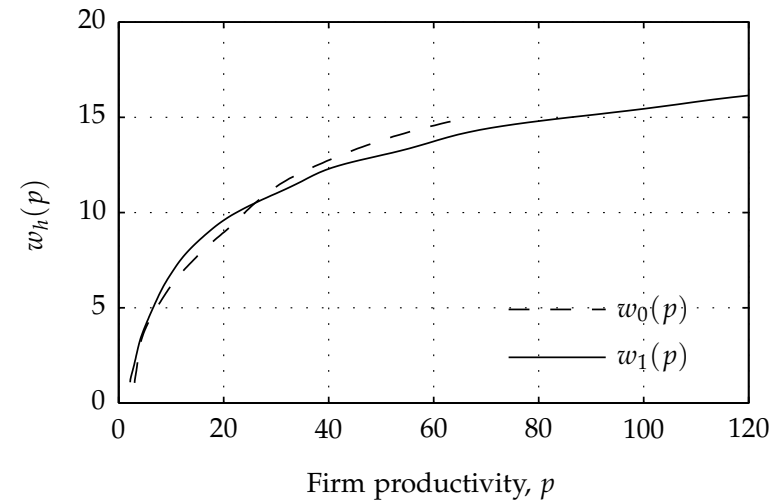

(a) Wage policy functions

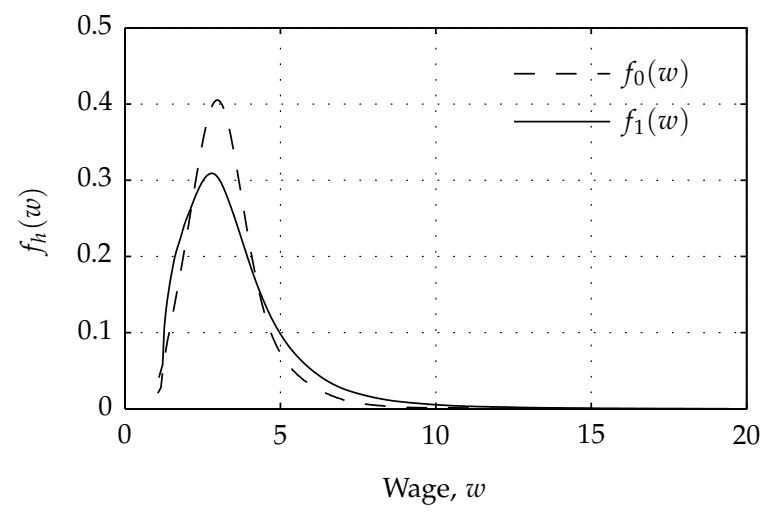

(c) Wage offer distributions

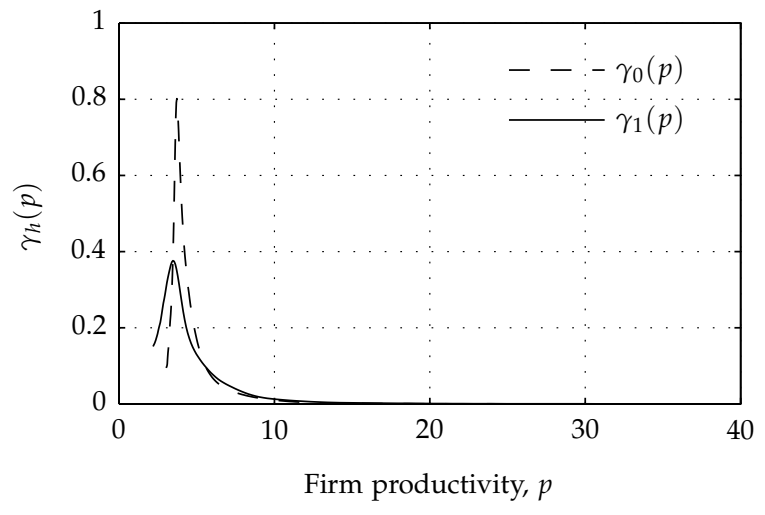

(b) Firms productivity distributions

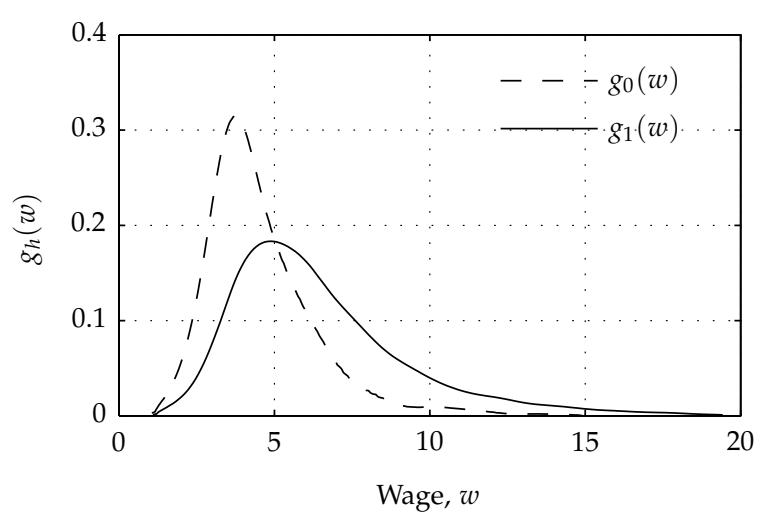

(d) Wage earnings distributions

Figure 2: Pre-reform equilibrium distributions and functions. All figures calculated using the maximum likelihood estimates from Table 1 and calculated under the April 1997 (pre-reform) tax and transfer system. All incomes measured in April 1997 prices. Figure 2a shows how the optimal wage policy of firms varies with hours and firm productivity, and truncated at productivities greater than $w_{1}^{-1}\left(\hat{G}_{1}(0.99)\right)$; Figure $2 \mathrm{~b}$ shows the underlying distribution of firm productivity as obtained from the first order conditions to the firms' profit maximization problem (with the normalization $v_{h}(p)=1$ ), and truncated at productivities greater than $w_{1}^{-1}\left(\hat{G}_{1}(0.95)\right)$; Figure $2 \mathrm{c}$ shows the associated distribution of part-time and full-time wage offers; Figure $2 \mathrm{~d}$ shows the unconditional distribution of part-time and full-time earnings that these wage offer distributions induce. 
the null hypothesis that the arrival rates are equal. These general findings are broadly consistent with the estimates reported in van den Berg and Ridder (1998); they contrast with Bontemps, Robin and van den Berg (2000) which found (using French Labour Force Survey data) that job offers arrive around ten times as frequently for the unemployed compared to the employed. For all groups of women we obtain the relative part-time arrival rate ratio $\hat{\lambda}_{e i}^{0} / \hat{\lambda}_{u i}^{0}<1$ (ranging from 1.3 for single parents to 5.7 for single women), but we can not reject the null hypothesis that this ratio equals one for single parents. Mirroring the pattern observed for men, the relative full-time job offer arrival rate ratio for single women $\hat{\lambda}_{e i}^{1} / \hat{\lambda}_{u i}^{1}=1.6$, while this ratio is again somewhat higher for married women without children $(=3.1)$ and lower for married women with children $(=0.7)$. For single parents we estimate large differences by employment status with $\hat{\lambda}_{e i}^{1} / \hat{\lambda}_{u i}=0.1$.

The estimated monetary disutility of full-time work $\hat{C}_{i}^{1}$ is lowest for single women (around $£_{19}$ per week in April 1997 prices), while it is at least twice as high for single parents and married women. We obtain considerable dispersion in the unobserved leisure flows for all groups, and this translates into dispersion in reservation wages. In the Supplementary Material we present results which show the proportion of workers of each type whose reservation wage is below given percentiles of the (full-time) wage offer distribution. In all cases we obtain $\hat{A}_{i}\left(\underline{\hat{w}}_{1}\right) \ll 1$, so that workers are indeed selective in the wage offers that they are willing to accept. This feature also implies a negative duration dependence in the exit rate out of unemployment. Furthermore, we find that essentially all individuals would be willing to accept the highest full-time wage offer.

Since the wage offer distributions are common to all workers, any difference in employment states and earnings distributions must be explained by variation in the transitional parameters, leisure flow distributions, and the tax and transfer system. Overall, we obtain a good fit to the data. The difference in the empirical and predicted states for the main demographic groups is small and only rarely does it exceed I percentage point (see Table 2). Similarly, we do well in replicating the observed distribution of wage earnings (see Figure 3); for most groups the fit is excellent, although the fit of the fulltime earnings distribution for married women with children (Figure $3 \mathrm{~h}$ ) is somewhat less satisfactory. 
Table 2: Empirical and Predicted Employment States

\begin{tabular}{|c|c|c|c|c|c|c|c|}
\hline & & \multicolumn{3}{|c|}{ Empirical } & \multicolumn{3}{|c|}{ Predicted } \\
\hline \multirow{8}{*}{ N } & & $u_{i}$ & $m_{0 i}$ & $m_{1 i}$ & $u_{i}$ & $m_{0 i}$ & $m_{1 i}$ \\
\hline & single men & $\begin{array}{c}0.251 \\
{[0.238,0.262]}\end{array}$ & - & $\begin{array}{c}0.749 \\
{[0.738,0.762]}\end{array}$ & $\begin{array}{c}0.241 \\
{[0.230,0.252]}\end{array}$ & - & $\begin{array}{c}0.759 \\
{[0.748,0.770]}\end{array}$ \\
\hline & married men, no kids & $\begin{array}{c}0.070 \\
{[0.061,0.079]}\end{array}$ & - & $\begin{array}{c}0.930 \\
{[0.921,0.939]}\end{array}$ & $\begin{array}{c}0.063 \\
{[0.056,0.071]}\end{array}$ & - & $\begin{array}{c}0.937 \\
{[0.929,0.944]}\end{array}$ \\
\hline & married men, kids & $\begin{array}{c}0.123 \\
{[0.114,0.131]}\end{array}$ & - & $\begin{array}{c}0.877 \\
{[0.869,0.886]}\end{array}$ & $\begin{array}{c}0.116 \\
{[0.110,0.123]}\end{array}$ & - & $\begin{array}{c}0.884 \\
{[0.877,0.890]}\end{array}$ \\
\hline & single women & 0.157 & $\begin{array}{c}0.102 \\
{[0.091 .0 .112]}\end{array}$ & $\begin{array}{c}0.741 \\
{[0.726 .0 .757]}\end{array}$ & $\begin{array}{c}0.166 \\
{[0.155 .0 .176]}\end{array}$ & $\begin{array}{c}0.106 \\
{[0.096 .0 .116]}\end{array}$ & $\begin{array}{c}0.728 \\
{[0.714 .0 .742]}\end{array}$ \\
\hline & single parents & {$[0.601$} & $\begin{array}{c}0.229 \\
{[0.216,0.242]}\end{array}$ & $\begin{array}{c}{[0 . / 170} \\
0.159 .0 .181]\end{array}$ & $\begin{array}{c}0.594 \\
{[0.580 .0 .609]}\end{array}$ & $\begin{array}{c}0.238 \\
{[0.2270 .251]}\end{array}$ & $\begin{array}{c}0.167 \\
{[0.156,0.179]}\end{array}$ \\
\hline & married women, no kids & $\begin{array}{c}0.130 \\
{[0.121,0.140]}\end{array}$ & $\begin{array}{c}0.224 \\
{[0.213,0.237]}\end{array}$ & $\begin{array}{c}0.646 \\
{[0.631,0.659]}\end{array}$ & $\begin{array}{c}0.131 \\
{[0.123,0.142]}\end{array}$ & $\begin{array}{c}0.228 \\
{[0.216,0.240]}\end{array}$ & $\begin{array}{c}0.641 \\
{[0.628,0.654]}\end{array}$ \\
\hline & married women, kids & $\begin{array}{c}0.342 \\
{[0.332,0.351]}\end{array}$ & $\begin{array}{c}0.409 \\
{[0.400,0.419]}\end{array}$ & $\begin{array}{c}0.249 \\
{[0.240,0.258]}\end{array}$ & $\begin{array}{c}0.339 \\
{[0.330,0.347]}\end{array}$ & $\begin{array}{c}0.412 \\
{[0.403,0.423]}\end{array}$ & $\begin{array}{c}0.248 \\
{[0.239,0.257]}\end{array}$ \\
\hline
\end{tabular}

Notes: Predicted states are calculated using the maximum likelihood estimates from Table 1 . Employment states may not sum to one due to rounding. The $5^{\text {th }}$ and $95^{\text {th }}$ percentiles of the bootstrap distribution of employment states are presented in brackets, and are calculated using 500 bootstrap replications. 


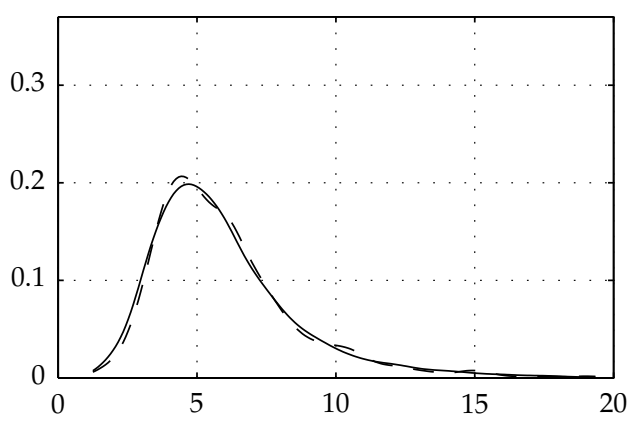

(a) Single men

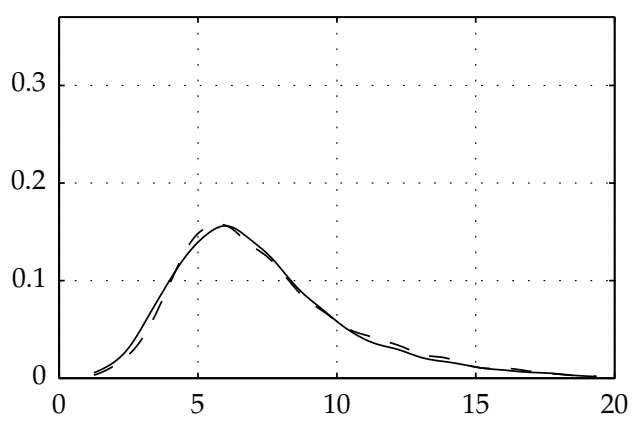

(c) Married men, kids

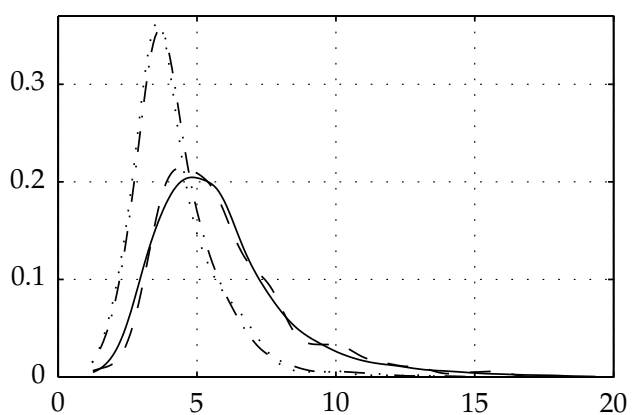

(e) Single parents

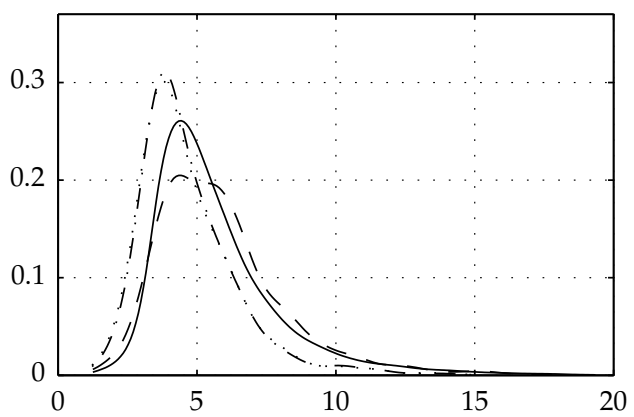

(g) Married women, kids

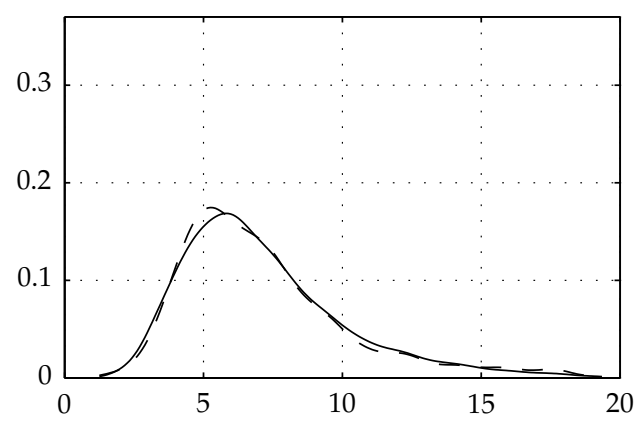

(b) Married men, no kids

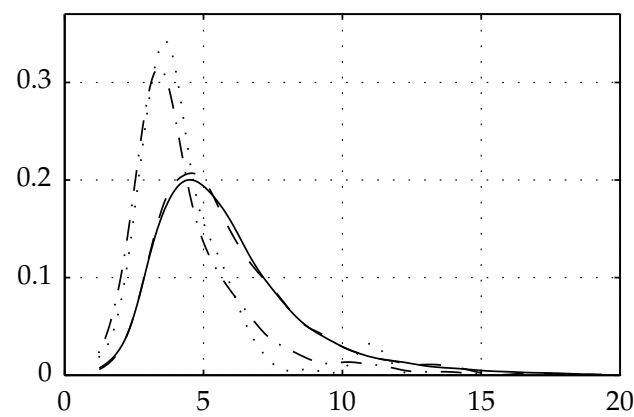

(d) Single women

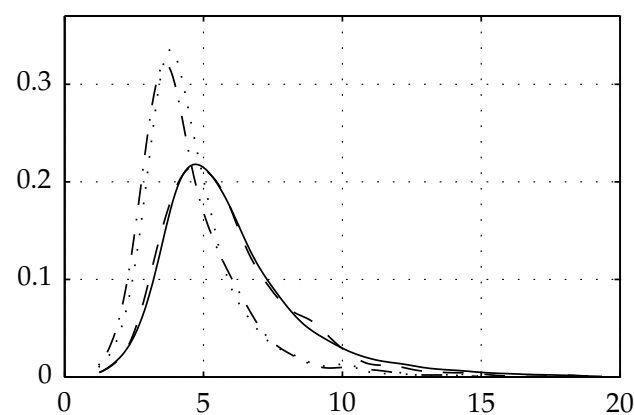

(f) Married women, no kids

$$
\begin{array}{r}
\hline- \text { simulated } g_{1 i}(w) \\
--- \text { simulated } g_{1 i}(w) \\
-\cdot-\text { - empirical } g_{0 i}(w) \\
\cdots \cdots \text { empirical } g_{0 i}(w)
\end{array}
$$

Figure 3: Simulated and empirical wage earnings by group. Horizontal axis refers to hourly wage rate in April 1997 prices; Vertical axis refers to wage density. Empirical distributions are calculated using a Gaussian kernel with a bandwidth of 0.5 . 


\section{Simulating Tax Reforms}

In this section we simulate the impact of real changes to the UK tax and transfer system between April 1997 (the pre-reform sample period) and April 2002. All the simulations in this section assume a quadratic recruiting cost technology $c_{h}(v ; p)=c_{h}(p) v^{2} / 2$. Under this specification, the simulations are invariant to the parametrization of $c_{h}(p)$ provided that $c_{h}(p)>0$ (see the Supplementary Material for a proof). Without loss of generality we set $v_{h}(p)=1$ in the pre-reform period and recover the values of $c_{h}(p)$ that are consistent with this being an equilibrium. This also implies that $\Gamma_{h}(p)=F_{h}\left(w_{h}(p)\right)$ under the base system. The simulations also assume the presence of Cobb-Douglas matching functions $M_{h}\left(V_{h}, S_{h}\right)=V_{h}^{\theta_{h}} S_{h}^{1-\theta_{h}}$ and we set $\theta_{0}=\theta_{1}=1 / 2$. Given equilibrium effects turn out to be small, our main results are not sensitive to these specific values.

To highlight the relative importance that these reforms have on job acceptance behavior and the strategy of firms, we present our results in two stages. Firstly, we consider the impact of the reforms holding the distribution of job offers and their arrival rates constant; secondly, we additionally allow firms to optimally respond by changing their wage policy and recruiting effort. We refer to the first channel as the direct impact of the reforms, and the second channel as the equilibrium impact of the reforms.

\subsection{Direct Impact}

The direct and equilibrium impact of the reforms on employment states is presented in Table 3, and we first discuss the direct effect. The table shows that the (non-WFTC) reforms had a small positive effect on the employment of both singles and couples without children (ranging from 0.2 percentage points for married men without children, to 0.9 percentage points for single men). These increases are primarily due to small reductions in the real value of out-of-work income, together with small reductions in income-tax which act to raise the value of holding low wage jobs and so lower reservation wages.

Perhaps unsurprisingly, the largest predicted impact of these reforms is on the employment rate of single parents, where we predict an increase of 5.6 percentage points. Despite both full-time and part-time reservation wages falling for many of these work$\mathrm{ers}^{24}$ this steady state employment increase is exclusively due to a movement into full-

\footnotetext{
${ }^{24}$ The reservation wages of individuals with very high $b$ will actually increase. These individuals experience an increase in their out-of-work income, but at the high wages that these workers would actually accept they will be ineligible for tax credits so there is little change in their net taxes when employed.
} 
Table 3: Employment Impact of Reforms

\begin{tabular}{|c|c|c|c|c|c|c|}
\hline & \multicolumn{3}{|c|}{ Direct Impact } & \multicolumn{3}{|c|}{ Equilibrium Impact } \\
\hline & $\Delta u_{i}$ & $\Delta m_{0 i}$ & $\Delta m_{1 i}$ & $\Delta u_{i}$ & $\Delta m_{0 i}$ & $\Delta m_{1 i}$ \\
\hline single men & $\begin{array}{c}-0.009 \\
{[-0.011,-0.007]}\end{array}$ & - & $\begin{array}{c}0.009 \\
{[0.007,0.011]}\end{array}$ & $\begin{array}{c}-0.011 \\
{[-0.014,-0.009]}\end{array}$ & - & $\begin{array}{c}0.011 \\
{[0.009,0.014]}\end{array}$ \\
\hline married men, no kids & {$\left[\begin{array}{c}-0.002 \\
{[-0.002,-0.001]}\end{array}\right.$} & - & $\begin{array}{c}0.002 \\
{[0.001,0.002]}\end{array}$ & $\begin{array}{c}-0.003 \\
{[-0.004,-0.002]}\end{array}$ & - & {$\left[\begin{array}{c}0.003 \\
{[0.002,0.004]}\end{array}\right.$} \\
\hline married men, kids & $\begin{array}{c}-0.015 \\
{[-0.020,-0.010]}\end{array}$ & - & $\begin{array}{c}0.015 \\
{[0.010,0.020]}\end{array}$ & $\begin{array}{c}-0.015 \\
{[-0.021,-0.011]}\end{array}$ & - & $\begin{array}{c}0.015 \\
{[0.011,0.021]}\end{array}$ \\
\hline single women & $\begin{array}{c}-0.005 \\
{[-0.006,-0.004]}\end{array}$ & $\begin{array}{c}-0.001 \\
{[-0.002,0.000]}\end{array}$ & $\begin{array}{c}0.006 \\
{[0.005,0.007]}\end{array}$ & $\begin{array}{c}-0.006 \\
{[-0.007,-0.005]}\end{array}$ & $\begin{array}{c}-0.005 \\
{[-0.007,-0.003]}\end{array}$ & $\begin{array}{c}0.010 \\
{[0.008,0.013]}\end{array}$ \\
\hline single parents & $\begin{array}{c}-0.056 \\
{[-0.073,-0.032]}\end{array}$ & $\begin{array}{c}-0.017 \\
{[-0.031,-0.007]}\end{array}$ & $\begin{array}{c}0.073 \\
{[0.055,0.088]}\end{array}$ & $\begin{array}{c}-0.053 \\
{[-0.069,-0.030]}\end{array}$ & $\begin{array}{c}-0.022 \\
{[-0.037,-0.013]}\end{array}$ & $\begin{array}{c}0.075 \\
{[0.057,0.091]}\end{array}$ \\
\hline married women, no kids & $\begin{array}{c}-0.004 \\
{[-0.004,-0.003]}\end{array}$ & $\begin{array}{c}-0.009 \\
{[-0.010,-0.007]}\end{array}$ & $\begin{array}{c}0.013 \\
{[0.011,0.014]}\end{array}$ & $\begin{array}{c}-0.004 \\
{[-0.005,-0.004]}\end{array}$ & $\begin{array}{c}-0.014 \\
{[-0.018,-0.011]}\end{array}$ & $\begin{array}{c}0.018 \\
{[0.015,0.022]}\end{array}$ \\
\hline married women, kids & $\begin{array}{c}0.013 \\
{[0.011,0.014]}\end{array}$ & $\begin{array}{c}-0.011 \\
{[-0.012,-0.009]}\end{array}$ & $\begin{array}{c}-0.002 \\
{[-0.003,-0.001]}\end{array}$ & $\begin{array}{c}0.015 \\
{[0.014,0.018]}\end{array}$ & $\begin{array}{c}-0.015 \\
{[-0.019,-0.013]}\end{array}$ & $\begin{array}{c}-0.000 \\
{[-0.002,0.002]}\end{array}$ \\
\hline
\end{tabular}

Notes: All employment responses are expressed in percentage points. Changes may not sum to zero due to rounding. The direct impact considers all changes to the tax and transfer system between April 1997 and April 2002, holding the wage offer distributions and arrival rates at their pre-reform levels. The equilibrium impact allows the wage offer distribution and arrival rates to change. 


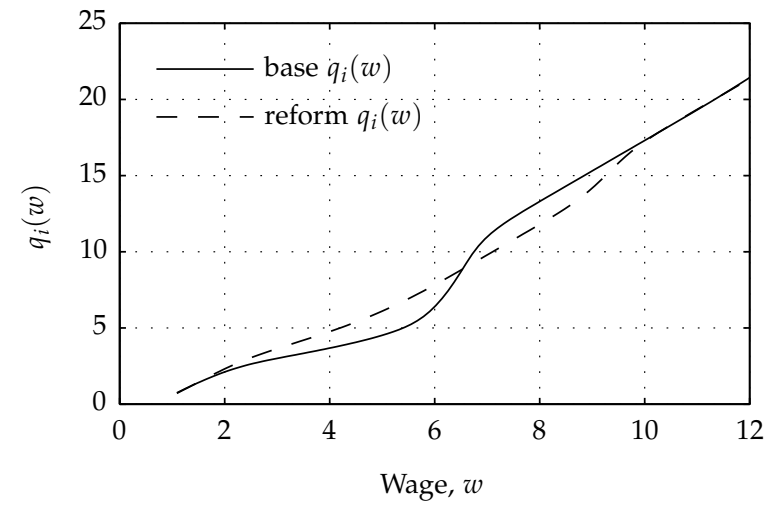

(a) Indifference condition

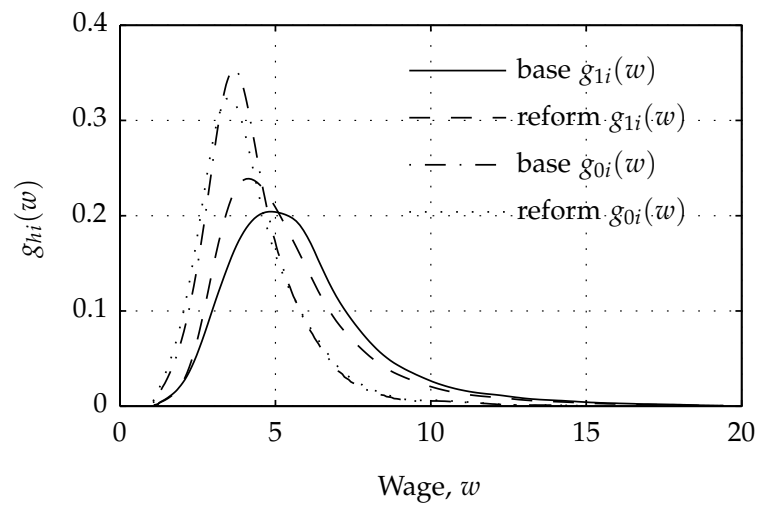

(b) Firms productivity distributions

Figure 4: Direct impact of tax reforms on single parents. Figure 4a shows the impact of the reforms on the indifference condition for a single parent with two children (truncated at full-time wages greater than £12); Figure $4 \mathrm{~b}$ shows the direct effect of the reforms on single parents' distribution of wage earnings. All incomes measured in April 1997 prices.

time work. This is because the lower withdrawal rate of WFTC compared to FC results in full-time incomes increasing by more than part-time incomes over a large range of wages for this group (Figure 4 a shows how the indifference condition $q_{i}(w)$ changes), and because of on-the-job search with the estimated arrival rate of full-time wage offers among the employed far exceeding that of part-time wage offers $\left(\lambda_{e i}^{1} \gg \lambda_{e i}^{0}\right)$.

For couples with children the impact of these reforms is more complicated as tax credit entitlement depends upon family income: individuals with a high earning partner are essentially unaffected by the reform; those with a non-working or very low earning partner respond positively, much like single parents; in intermediate cases, movement into work can result in tax credit awards being withdrawn which may induce negative labor supply responses (particularly among the newly eligible families). On balance, these factors lead to a small decrease in the employment of married women with children (a 1.3 percentage point decrease), and increase the employment rate of married men with children by a similar absolute magnitude. Among married women, this decrease in labor supply comes primarily through a reduction in those working part-time. The potential disincentive effects of tax credits programs on family labor supply have long been recognized, with the direction of these responses consistent with those reported in other studies (see for example, Eissa and Hoynes, 2004).

Before we discuss the equilibrium impact of the reforms, we briefly discuss the effect on wages. Note that selection alone imply that wage earnings will change even though 
the distribution of wage offers is held fixed. This highlights the fact that attempting to estimate the incidence of tax credit programs by comparing changes in observed wages amongst eligible and non-eligible groups is potentially misleading without carefully controlling for these dynamic selection effects. Indeed, selection alone implies some large reductions in full-time average wages. Our simulations imply that single parents experience a $7 \%$ reduction in average full-time wage earnings and a $1 \%$ reduction in part-time wages (see Figure $4 \mathrm{~b}$ ). The changes for other groups are much smaller.

\subsection{Equilibrium Impact}

In Table 3 we also present the equilibrium impact. The first immediate thing to note is that the impacts are generally very similar to those obtained from the direct impact. That is, equilibrium considerations do not appear to be very important for this particular set of reforms. Looking more closely we can see that equilibrium considerations tend to increase employment in full-time jobs, and decrease employment in part-time jobs.

Given the small magnitude of the changes here, we do not attempt to describe the responses in detail. We note, however, that the direction of the changes to firms' optimal policies can largely be understood by examining the initial direct impact of the reforms on labor supply. The reduction in reservation wages experienced by many workers raises both part-time and full-time employment at low wages. However, the changes to the indifference conditions as noted above also induce transitions between the hours sectors. The net effect of these transitions means that part-time employment falls at moderate wage levels. Part-time firms which experienced initial increases in their employment generally respond by lowering their wage offers in the new equilibrium and increasing their recruiting intensity; at slightly higher wage rates where employment initially falls we find the opposite effect. Full-time firms have smaller adjustments in their wages (although it is still the case that the firms which experienced the largest initial increase in employment tend to have the greatest reduction in wages), with the majority of the response for these firms coming through changes in recruiting intensity. In Figure 5 we illustrate these relative change in firms' strategies.

\subsection{Other Evaluations}

The set of tax reforms considered here have been the subject of a number of other studies, with difference-in-differences being the most common empirical approach (see Brewer 


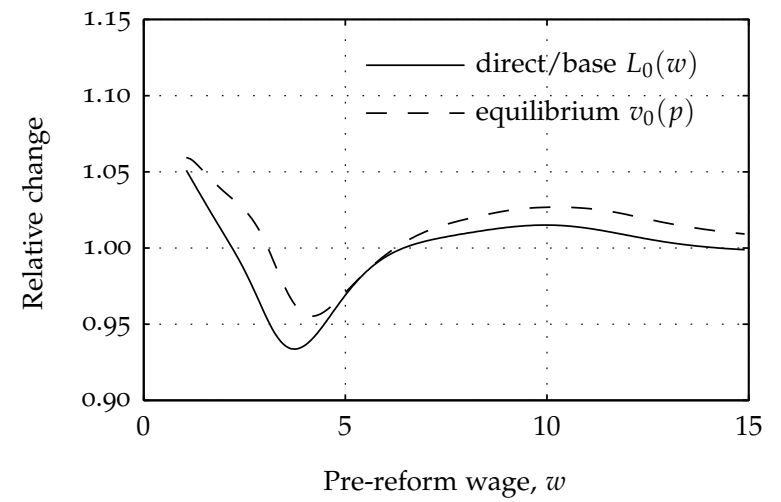

(a) Part-time recruiting intensity

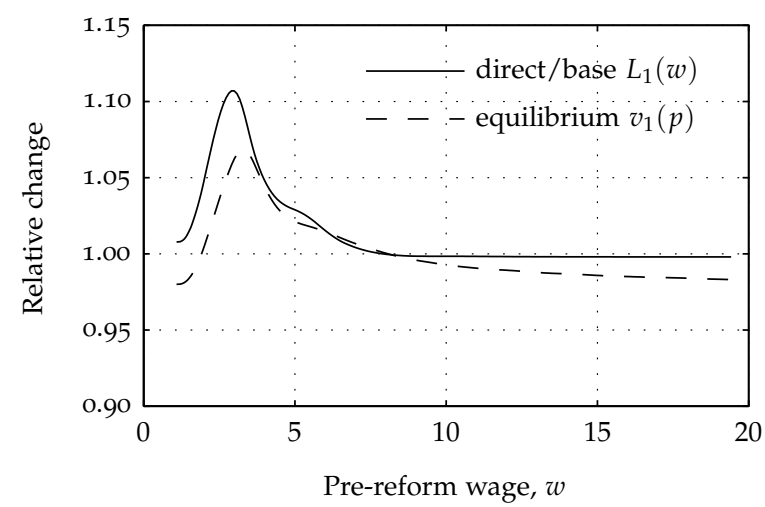

(c) Full-time recruiting intensity

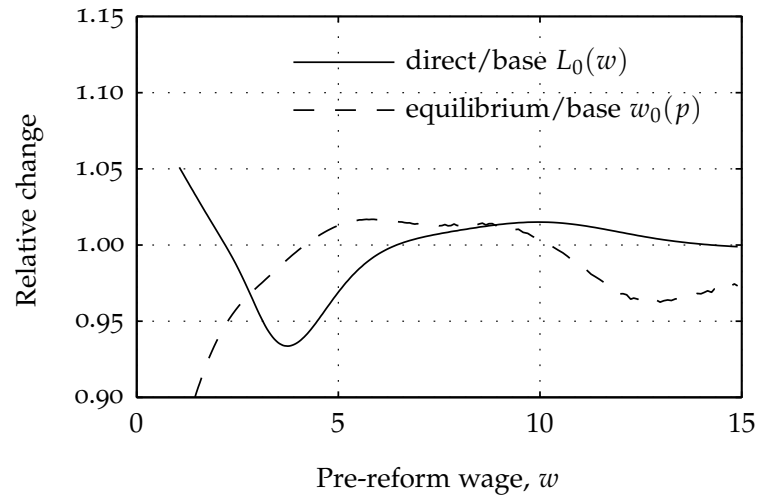

(b) Part-time wage policy

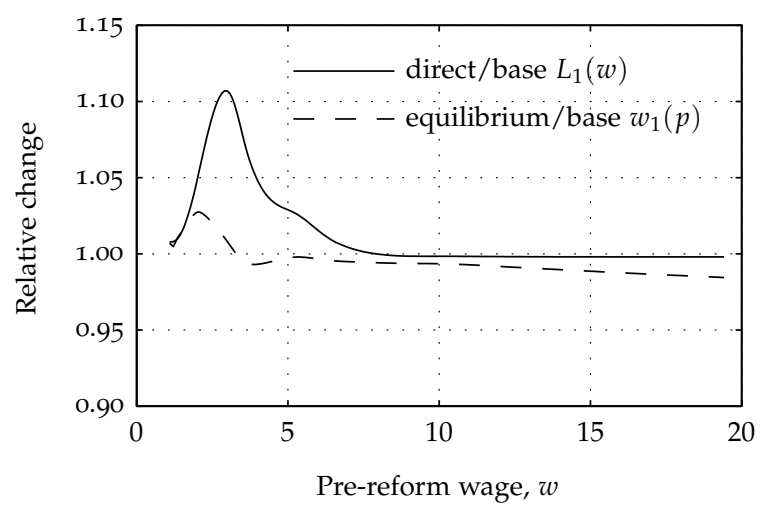

(d) Full-time wage policy

Figure 5: Equilibrium policy responses. Figures $5 \mathrm{a}$ and $5 \mathrm{c}$ show how the equilibrium recruiting intensity of part-time and full-time firms (as identified by their pre-reform wage policy) changes, and how this compares to the relative direct employment responses. Similarly, Figures 5b and 5d show how the equilibrium wage policy of part-time and full-time firms changes, and again compares this to the relative direct employment responses. All incomes measured in April 1997 prices. 
and Browne, 2006, for a survey). These evaluations have largely (but not exclusively) focused upon the impact on single parents and essentially involve comparing the changing employment outcomes of single mothers to single women without children. The quantitative impact reported in these studies is remarkably similar to those in Table 3. This is perhaps unsurprising given that we did not find evidence of strong equilibrium effects in our analysis (if they were important then the usual stable unit treatment value assumption would be violated). The employment impact is also similar to that reported in studies using discrete choice techniques (for example, Blundell and Shephard, 2011).

\subsection{Post-reform Comparison}

We now compare our results to the actual changes to employment states between 1997 and 2002 - tabulations are presented in the Supplementary Material. Over this period, all the broad demographic groups experienced an increase in their employment rate. And for all groups except single men and married women with children, we systematically under-predict the growth in employment by between around one and one-and-a-half percentage points. For single men and particularly married women with children, the extent of under-prediction is larger. Overall, this suggests that non-tax changes over this period, including robust productivity growth, changes in the distribution of partner earnings, the introduction of a national minimum wage, and various "New Deal" active labor market policies (particularly relevant for low skilled men) were also important for understanding the changing labor market outcomes. Finally, we note that the model is somewhat less successful in explaining the changing distribution of work hours. For single parents, the empirical increase in employment is evenly split between movements into both part-time and full-time employment; this contrasts with our simulations which suggested that it was exclusively due to a movement into full-time work.

\subsection{Why Aren't Equilibrium Effects More Important?}

Our analysis suggests that equilibrium effects may be small. We now explore the extent to which this may be due to the integrated nature of the labor market and the targeted nature of the reforms. While allowing all workers to compete within the same market was a natural characterization of the labor market, and one which permitted spillover effects, it limits the potential for sizable equilibrium effects following a targeted reform 
like WFTC if firms are constrained to have a single wage policy. ${ }^{25}$ To understand the importance of these assumptions we now consider - for illustrative purposes - a labor market comprised of single parents and married men with children. These were the two groups with the largest simulated employment response. ${ }^{26}$ Under this assumption we obtain larger within-market equilibrium effects. There are now larger changes in the optimal policies of firms (particularly in the part-time sector) which result in a reduced employment response for single parents: equilibrium considerations now reduce the employment increase to 4.5 percentage points (the direct impact is reduced by $22 \%$ ). Equilibrium responses, as before, act to slightly increase employment for married men with children. However, there is little additional impact relative to the results reported in Table 3 as the change in policy responses is concentrated among part-time firms.

\section{Conclusion}

This paper has developed an empirical equilibrium job search model with wage posting, and has used it to analyze the impact of a series of UK tax reforms that included the Working Families' Tax Credit reform. It presents a synthesis of existing equilibrium job search models, and extends them in a number of dimensions to reflect key features of the UK labor market and to allow for the possibility of rich equilibrium effects.

We structurally estimate the model using a semi-parametric estimation procedure, and predict that the tax reforms had a positive effect on the employment of most groups, with single parents experiencing the largest employment increase. Our simulations suggest that while equilibrium effects do play a role, the changes in labor market outcomes are dominated by the direct effect of changing job acceptance behavior. And while these reforms appear to be able to explain some of the actual changes in employment over the relevant period, for some groups other changes in the economy appear more important.

Even though these equilibrium effects may not appear very large for this particular set of reforms, it does not imply that they should always be ignored. Recalling that WFTC is only available to families with children, these equilibrium effects have the

${ }^{25}$ In a model with worker and firm bargaining, wages essentially become individualistic so that the potential for equilibrium effects is much larger. Lise, Seitz and Smith (2005) used such a model in their analysis of the Canadian Self-Sufficiency Project, and found substantial equilibrium effects.

${ }^{26}$ To ensure that the direct impacts remain as in Table 3 we do not re-estimate the model. Instead, we use the same parameter estimates from Table $I$ (with the associated non-parametric estimates of $F_{h}$ ), and recover the distribution of firm productivity under alternative market segmentation assumptions. We also attempted this exercise using a market comprised solely of single parents, but encountered large monotonicity violations when using firms' first order conditions to recover the distributions of productivity. 
potential to be more important for reforms that are less targeted. We also demonstrate that the within market equilibrium effects of the same reforms may be much larger if we consider a somewhat more segmented labor market.

We believe that this paper represents an important step in using empirical equilibrium job search models to evaluate the impact of tax policies. Despite performing our empirical analysis on individuals with low education levels, it is likely that differences in worker ability persist. A natural extension could therefore involve incorporating heterogeneity in worker productivity which necessitates a more detailed modeling of firm

production technologies. Furthermore, given that the tax and transfer systems of many countries depend upon family income to some extent, a more detailed characterization of the behavior of couples would allow us to explore the impact of policies on household labor supply allocations. Finally, given the importance of labor supply in our simulations, incorporating a micro-level search intensity choice would create a further dimension along which individuals can respond. While each of these represent non-trivial extensions, it does suggest a very exciting agenda of future research.

\section{References}

Adam, Stuart, and James Browne. 2009. "A survey of the UK tax system." IFS Briefing Notes, BNog.

Albrecht, James W., and Bo Axell. 1984. "An Equilibrium Model of Search Unemployment." The Journal of Political Economy, 92(5): 824-840.

Altonji, Joseph G., and Christina H. Paxson. 1988. "Labor Supply Preferences, Hours Constraints, and Hours-Wage Trade-offs." Journal of Labor Economics, 6(2): 254-276.

Azmat, Ghazala. 2006. "The Incidence of an Earned Income Tax Credit: Evaluating the Impact on Wages in the UK." CEP Discussion Paper, Paper No: CEPDPo724.

Barlevy, Gadi. 2008. "Identification of Search Models using Record Statistics." Review of Economic Studies, 75(1): 29-64.

Barlevy, Gadi, and H. N. Nagaraja. 2006. "Identification of Search Models with Initial Condition Problems." Working Paper No. 2006-03, Federal Reserve Bank of Chicago.

Blau, David M. 1991. "Search for Nonwage Job Characteristics: A Test of the Reservation Wage Hypothesis." Journal of Labor Economics, 9(2): pp. 186-205. 
Blundell, R., and H. Hoynes. 2004. "Has "In-Work" Benefit Reform Helped the Labor Market?" In Seeking a Premier Economy: The Economic Effects of British Economic Reforms, 1980-2000. , ed. Richard Blundell, David Card and Richard B. Freeman, 411-459. Chicago:University Of Chicago Press.

Blundell, Richard, and Andrew Shephard. 2011. "Employment, hours of work and the optimal taxation of low income families." Review of Economic Studies, Forthcoming.

Blundell, Richard, Mike Brewer, and Marco Francesconi. 2008. "Job changes, hours changes and the path of labour supply adjustment." Journal of Labor Economics, 26(3): 421-453.

Blundell, R., M. Costa Dias, C. Meghir, and J. Van Reenen. 2004. "Evaluating the Employment Impact of a Mandatory Job Search Program." Journal of the European Economic Association, 2(4): 569-606.

Bontemps, Christian, Jean-Marc Robin, and Gerard J. van den Berg. 1999. "An Empirical Equilibrium Job Search Model with Search on the Job and Heterogeneous Workers and Firms." International Economic Review, 40(4): 1039-1074.

Bontemps, Christian, Jean-Marc Robin, and Gerard J. van den Berg. 2000. "Equilibrium Search with Continuous Productivity Dispersion: Theory and Nonparametric Estimation." International Economic Review, 41(2): 305-358.

Bound, John, Charles Brown, Greg J. Duncan, and Willard L. Rodgers. 1994. “Evidence on the Validity of Cross-Sectional and Longitudinal Labor Market Data." Journal of Labor Economics, 12(3): pp. 345-368.

Brewer, Mike. 2001. "Comparing in-work benefits and the reward to work for families with children in the US and the UK." Fiscal Studies, 22(1): 41-77.

Brewer, Mike, and James Browne. 2006. "The effect of the working families' tax credit on labour market participation." Briefing Note 69, Institute for Fiscal Studies, London.

Burdett, Kenneth, and Dale T. Mortensen. 1998. "Wage Differentials, Employer Size, and Unemployment." International Economic Review, 39(2): 257-273.

Chernozhukov, Victor, Ivan Fernandez-Val, and Alfred Galichon. 2007. "Improving Estimates of Monotone Functions By Rearrangement." Biometrika, Forthcoming. 
Christensen, Bent Jesper, Rasmus Lentz, Dale T. Mortensen, George R. Neumann, and Axel Werwatz. 2005. "On the Job Search and the Wage Distribution." Journal of Labor Economics, 23(1): 31-58.

Eissa, Nada, and Hilary Williamson Hoynes. 2004. "Taxes and the labor market participation of married couples: the earned income tax credit." Journal of Public Economics, 88(9-10): 1931-1958.

Gentry, William M., and R. Glenn Hubbard. 2004. "The effects of progressive income taxation on job turnover." Journal of Public Economics, 88(11): 2301-2322.

Guler, Bulent, Fatih Guvenen, and Giovanni L. Violante. 2009. "Joint-Search Theory: New Opportunities and New Frictions." NBER Working Paper 15011.

Hall, Robert E., and Alan B. Krueger. 2008. "Wage Formation between Newly Hired Workers and Employers: Survey Evidence." NBER Working Paper 14329.

Hotz, V. Joseph, and John Karl Scholz. 2003. "The Earned Income Tax Credit." In MeansTested Transfer Programs in the U.S.. , ed. Robert Moffitt, 141-198. Chicago: University of Chicago Press.

Hwang, Hae-Shin, Dale T. Mortensen, and W. Robert Reed. 1998. "Hedonic Wages and Labor Market Search." Journal of Labor Economics, 16(4): 815-847.

Jin, Wencaho, Peter Levell, and David Phillips. 2010. "A survey of the UK benefit system." IFS Briefing Notes, BN13.

Jolivet, Grégory, Fabien Postel-Vinay, and Jean-Marc Robin. 2006. "The empirical content of the job search model: Labor mobility and wage distributions in Europe and the US." European Economic Review, 50(4): 877-907.

Kiefer, Nicholas M., and George R. Neumann. 1993. "Wage Dispersion with Homogeneity: The Empirical Equilibrium Search Model." In Panel Data and Labour Market Dynamics. , ed. H. Bunzel, P. Jensen and N. Westergård-Nielsen, 57-74. North-Holland.

Leigh, Andrew. 2010. "Who Benefits from the Earned Income Tax Credit? Incidence among Recipients, Coworkers and Firms." B.E. Journal of Economic Analysis E Policy, 10(1). 
Lise, Jeremy, Shannon N. Seitz, and Jeffrey Smith. 2005. "Equilibrium Policy Experiments and the Evaluation of Social Programs." Working Paper 1076, Queen's University, Department of Economics.

MaCurdy, Thomas, David Green, and Harry Paarsch. 1990. "Assessing Empirical Approaches for Analyzing Taxes and Labor Supply." The Journal of Human Resources, 25(3): 415-490.

Manning, Alan. 2003. Monopsony in Motion: Imperfect Competition in Labor Markets. Princeton University Press.

Meghir, Costas, Renata Narita, and Jean-Marc Robin. 2010. "Wages and Informality in Developing Countries." University College London, Mimeo.

Metcalf, David. 2008. "Why has the British national minimum wage had little or no impact on employment?" Journal of Industrial Relations, 50(3): 489-512.

Mortensen, Dale T. 2000. "Equilibrium unemployment with wage posting: BurdettMortensen meets Pissarides." In Data and Structural Labor Market Models. , ed. H. Bunzel, B.J. Christiansen, P. Jensen, N.M. Kiefer and D.T. Mortensen. Amsterdan: Elsevier.

Mortensen, Dale T., and George R. Neumann. 1988. "Estimating structural models of unemployment and job duration." Proceedings of the Third International Symposium in Economic Theory and Econometrics, Cambridge University Press.

Roger, Muriel, and Sébastien Roux. 2009. “Demande de travail et élasticité des heures au salaire." Recherches économiques de Louvain, 75(1): 63-91.

Rothstein, Jesse. 2008. "The Unintended Consequences of Encouraging Work: Tax Incidence and the EITC." Princeton University, Mimeo.

Rothstein, Jesse. 2009. "Is the EITC as Good as an NIT? Conditional Cash Transfers and Tax Incidence." American Economic Journal: Economic Policy. Forthcoming.

Shephard, Andrew. 2009. "FORTAX: Reference Manual." Unpublished Manuscript.

van den Berg, Gerard J., and Geert Ridder. 1998. "An Empirical Equilibrium Search Model of the Labor Market." Econometrica, 66(5): 1183-1221.

van den Berg, Gerard J., and Geert Ridder. 2003. "Measuring Labor Market Frictions: A Cross-Country Comparison." Journal of the European Economic Association, 1(1): 224-244. 


\section{Online Supplement to "Equilibrium Search and Tax Credit Reform"}

These online appendices (i) present some additional descriptive and results tables, (ii) provide proposition proofs, (iii) describe the tax rate schedule smoothing, and (iv) outline the numerical algorithm used to solve the model.

\section{A Additional Parameter and Results Table}

In Table S1 we present some data summary statistics; in Table S2 we present results which show the proportion of workers of each type whose reservation wage is below given percentiles of the (full-time) wage offer distribution, as described in Section 3.6 from the main text; in Table $S_{3}$ we compare the predicted changes from the model to the actual changes based on our sample selection criteria, and as discussed in Section 4.4 from the main text.

\section{B Proof of Proposition 2}

In this appendix we derive the optimal reservation wage strategies of unemployed workers that were presented in Section 2.2 from the main text. For notational simplicity, we do not explicitly write the value functions or the resultant reservation wages as a function of the unobserved leisure flow $b$. The value of unemployment $V_{u i}$ must satisfy:

$$
\begin{aligned}
\rho_{i} V_{u i}=b-T_{i}^{u} & +\lambda_{u i}^{0} \mathbb{E}_{w \sim F_{0}} \max \left\{V_{e i}^{0}(w)-V_{u i}, 0\right\} \\
& +\lambda_{u i}^{1} \mathbb{E}_{w \sim F_{1}} \max \left\{V_{e i}^{1}(w)-V_{u i}, 0\right\}
\end{aligned}
$$

where $V_{e i}^{0}(w)$ and $V_{e i}^{1}(w)$ are the values of part-time and full-time employment when receiving wage $w$, and where $\mathbb{E}_{w \sim F_{h}}$ indicates that the expectation is taken over the random variable $w$ with cumulative distribution function $F_{h}$. For workers who are employed in a part-time job $\left(h=h_{0}\right)$ we have:

$$
\begin{aligned}
\rho_{i} V_{e i}^{0}(w)=w h_{0}-T_{i}^{0}\left(w h_{0}\right) & +\lambda_{e i}^{0} \mathbb{E}_{x \sim F_{0}} \max \left\{V_{e i}^{0}(x)-V_{e i}^{0}(w), 0\right\} \\
& +\lambda_{e i}^{1} \mathbb{E}_{x \sim F_{1}} \max \left\{V_{e i}^{1}(x)-V_{e i}^{0}(w), 0\right\}+\delta_{i}\left(V_{u i}-V_{e i}^{0}(w)\right)
\end{aligned}
$$


Table S1: Descriptive Statistics

\begin{tabular}{|c|c|c|c|c|c|c|c|c|c|c|c|}
\hline & \multicolumn{4}{|c|}{ Unemployed } & \multicolumn{7}{|c|}{ Employed } \\
\hline & $\# N_{u}$ & $u \rightarrow h_{0}$ & $u \rightarrow h_{1}$ & $\overline{\# w_{u}}$ & $\# N_{e}^{0}$ & $\# N_{e}^{1}$ & $e \rightarrow h_{0}$ & $e \rightarrow h_{1}$ & $e \rightarrow u$ & $\# w_{e}^{0}$ & $\# w_{e}^{1}$ \\
\hline single men & 796 & - & 149 & 59 & - & 2372 & - & 96 & 98 & - & 1341 \\
\hline married men, no kids & 132 & - & 36 & 16 & - & 1763 & - & 74 & 29 & - & 1223 \\
\hline married men, kids & 504 & - & 99 & 57 & - & 3602 & - & 134 & 97 & - & 2472 \\
\hline single women & 357 & 26 & 33 & 38 & 233 & 1685 & 13 & 63 & 52 & 135 & 1054 \\
\hline single parents & 1661 & 100 & 12 & 89 & 630 & 467 & 28 & 18 & 65 & 421 & 325 \\
\hline married women, no kids & 417 & 25 & 22 & 28 & 720 & 2076 & 23 & 74 & 87 & 541 & 1481 \\
\hline married women, kids & 2176 & 204 & 42 & 154 & 2594 & 1583 & 91 & 55 & 180 & 1953 & 1168 \\
\hline
\end{tabular}

Notes: $\# N_{u}$ refers to the number of unemployed observations in a given category; $\# N_{e}^{0}$ and $\# N_{e}^{1}$ respectively refer to the number of part-time and full-time employment observations. \# $w_{u}$ refers to the number of observed accepted wages from unemployment; $\# w_{e}^{0}$ and $\# w_{e}^{1}$ refer to the number of cross-sectional wage observations in part-time and full-time employment. $i \rightarrow j$ refers to the numbers of observed transitions from state $i$ to state $j$, with states $u, e, h_{0}$ and $h_{1}$, denoting unemployment, overall employment, part-time employment, and full-time employment respectively. 


\section{Table S1: (continued)}

\begin{tabular}{|c|c|c|c|c|c|c|c|c|c|c|c|c|c|c|}
\hline & \multicolumn{7}{|c|}{ Part-time wages } & \multicolumn{7}{|c|}{ Full-time wages } \\
\hline & $P_{10}$ & $P_{25}$ & $P_{50}$ & $P_{75}$ & $P_{90}$ & mean & $\mathrm{SD}$ & $P_{10}$ & $P_{25}$ & $P_{50}$ & $P_{75}$ & $P_{90}$ & mean & $\mathrm{SD}$ \\
\hline single men & - & - & - & - & - & - & - & 3.41 & 4.15 & $5 \cdot 35$ & 7.02 & $9 \cdot 35$ & 5.93 & 2.61 \\
\hline married men, no kids & - & - & - & - & - & - & - & 4.05 & 5.00 & 6.48 & 8.45 & 11.28 & 7.14 & 3.06 \\
\hline married men, kids & - & - & - & - & - & - & - & 3.93 & 5.05 & 6.67 & 8.98 & 11.82 & $7 \cdot 33$ & 3.17 \\
\hline single women & 2.74 & 3.18 & 3.84 & 4.93 & 6.09 & $4 \cdot 32$ & 1.88 & $3 \cdot 31$ & 4.03 & 5.22 & 7.06 & 9.26 & 5.83 & 2.53 \\
\hline single parents & 2.63 & 3.24 & 3.78 & 4.79 & 6.13 & 4.16 & 1.50 & $3 \cdot 56$ & 4.18 & 5.44 & 7.03 & 9.26 & $5 \cdot 91$ & 2.41 \\
\hline married women, no kids & 2.99 & $3 \cdot 51$ & 4.11 & 5.12 & 6.57 & $4 \cdot 56$ & 1.75 & $3 \cdot 44$ & 4.23 & $5 \cdot 40$ & 6.98 & 8.88 & 5.84 & 2.33 \\
\hline married women, kids & 2.94 & $3 \cdot 47$ & 4.19 & $5 \cdot 47$ & 6.83 & 4.65 & 1.79 & $3 \cdot 44$ & 4.19 & $5 \cdot 45$ & 6.80 & 8.69 & 5.83 & 2.30 \\
\hline
\end{tabular}

Notes: All wages are hourly and are expressed in April 1997 prices. $P_{10}, P_{25}, P_{50}, P_{75}$, and $P_{90}$ respectively refer to the $10^{\text {th }}, 25^{\text {th }}, 50^{\text {th }}, 75^{\text {th }}$, and $90^{\text {th }}$ percentiles of the cross-sectional hourly wage distribution; SD refers to the standard deviation. 
Table S2: Reservation Wage Distribution

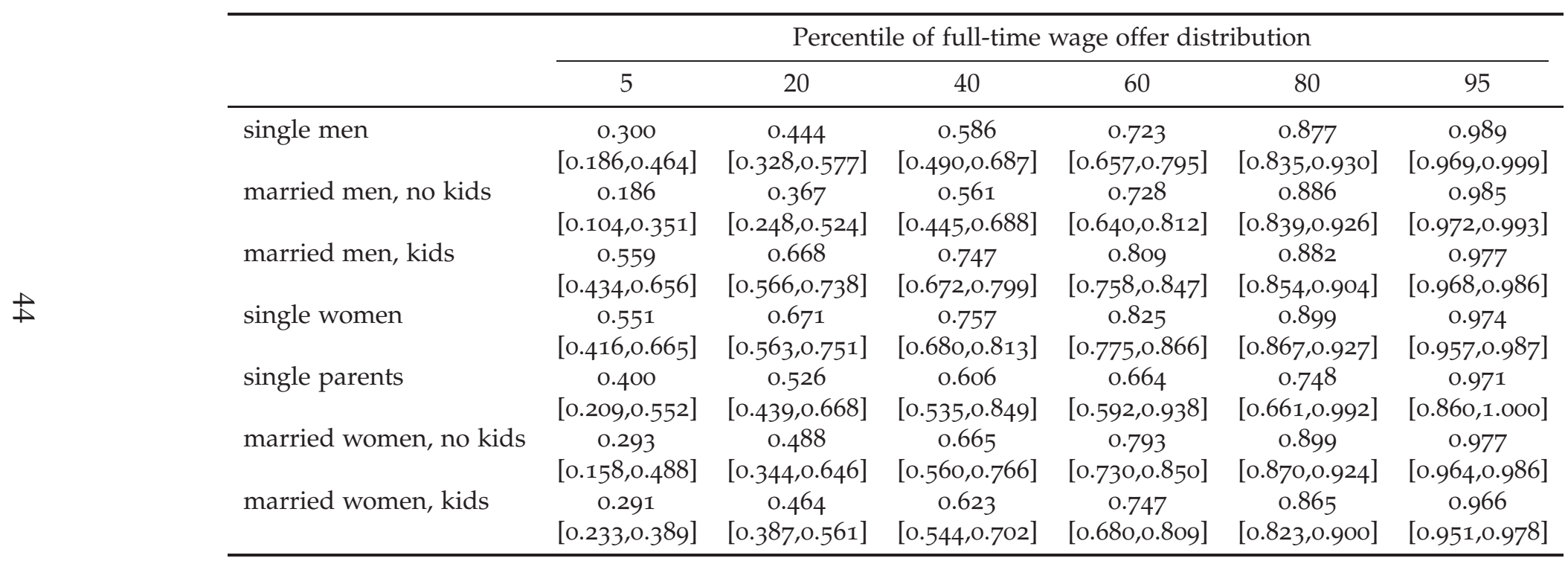

Notes: Table shows the fraction of individuals whose full-time reservation wage is below various percentiles $p$ of the full-time wage offer distribution, $A_{i}\left(\hat{F}_{1}^{-1}(p)\right)$, and is calculated using the maximum likelihood estimates from Table 1 . The $5^{\text {th }}$ and $95^{\text {th }}$ percentiles of the bootstrap distribution are presented in brackets, and are calculated using 500 replications. 
Table S3: Post-reform Comparison

\begin{tabular}{lccccccc}
\hline & \multicolumn{3}{c}{ Empirical } & & \multicolumn{3}{c}{ Predicted } \\
\cline { 2 - 3 } \cline { 7 - 8 } & $\Delta u_{i}$ & $\Delta m_{0 i}$ & $\Delta m_{1 i}$ & & $\Delta u_{i}$ & $\Delta m_{0 i}$ & $\Delta m_{1 i}$ \\
\hline single men & -0.050 & - & 0.050 & & -0.011 & - & 0.011 \\
married men, no kids & -0.019 & - & 0.019 & & -0.003 & - & 0.003 \\
married men, kids & -0.031 & - & 0.031 & -0.015 & - & 0.015 \\
single women & -0.018 & 0.005 & 0.012 & & -0.006 & -0.005 & 0.010 \\
single parents & -0.065 & 0.031 & 0.034 & -0.053 & -0.022 & 0.075 \\
married women, no kids & -0.023 & -0.012 & 0.035 & & -0.004 & -0.014 & 0.018 \\
married women, kids & -0.034 & 0.007 & 0.028 & & 0.015 & -0.015 & -0.000 \\
\hline
\end{tabular}

Notes: All employment responses are expressed in percentage points. Changes may not sum to zero due to rounding. The direct impact considers all changes to the tax and transfer system between April 1997 and April 2002, holding the wage offer distributions and arrival rates at their pre-reform levels. The equilibrium impact allows the wage offer distribution and arrival rates to change.

and for workers employed in a full-time job $\left(h=h_{1}\right)$ :

$$
\begin{aligned}
\rho_{i} V_{e i}^{1}(w)=w h_{1}-T_{i}^{1}\left(w h_{1}\right)-C_{i}^{1} & +\lambda_{e i}^{0} \mathbb{E}_{x \sim F_{0}} \max \left\{V_{e i}^{0}(x)-V_{e i}^{1}(w), 0\right\} \\
& +\lambda_{e i}^{1} \mathbb{E}_{x \sim F_{1}} \max \left\{V_{e i}^{1}(x)-V_{e i}^{0}(w), 0\right\}+\delta_{i}\left(V_{u i}-V_{e i}^{1}(w)\right) .
\end{aligned}
$$

Recalling that $q_{i}(w)$ is defined such that $V_{e i}^{1}(w)=V_{e i}^{0}\left(q_{i}(w)\right)$, it follows that the value of a full-time job at wage $w$ may be written as:

$$
\begin{aligned}
\rho_{i} V_{e i}^{1}(w)=w h_{1}-T_{i}^{1}\left(w h_{1}\right)-C_{i}^{1} & +\lambda_{e i}^{0} \int_{q_{i}(w)}^{\bar{w}_{0}}\left(V_{e i}^{0}(x)-V_{e i}^{1}(w)\right) d F_{0}(x) \\
& +\lambda_{e i}^{1} \int_{w}^{\bar{w}_{1}}\left(V_{e i}^{1}(x)-V_{e i}^{1}(w)\right) d F_{1}(x)+\delta_{i}\left(V_{u i}-V_{e i}^{1}(w)\right) .
\end{aligned}
$$

Equating equation S2 (evaluated at wage $w$ ) with the analogous expression for part-time employment (evaluated at wage $q_{i}(w)$ ) implies that $q_{i}(w)$ is the solution to:

$$
w h_{1}-T_{i}^{1}\left(w h_{1}\right)-C_{i}^{1}=q_{i}(w) h_{0}-T_{i}^{0}\left(q_{i}(w) h_{0}\right)
$$

which is equation 1 from the main text. We obtain this simple expression because, conditional on being in employment, both the destruction rate and arrival rates for full-time and part-time jobs are assumed independent of work hours so that it is only necessary 
to compare the instantaneous utility flows. Note also that:

$$
q_{i}^{\prime}(w)=\frac{h_{1}}{h_{0}} \cdot \frac{1-T_{i}^{1 \prime}\left(w h_{1}\right)}{1-T_{i}^{0 \prime}\left(q_{i}(w) h_{0}\right)} .
$$

To calculate the reservation wage we proceed by first performing integration by parts on equation S2 to obtain:

$$
\begin{aligned}
\rho_{i} V_{e i}^{1}(w)=w h_{1}-T_{i}^{1}\left(w h_{1}\right)-C_{i}^{1} & +\lambda_{e i}^{0} \int_{q_{i}(w)}^{\bar{w}_{0}} \bar{F}_{0}(x) d V_{e i}^{0}(x) \\
& +\lambda_{e i}^{1} \int_{w}^{\bar{w}_{1}} \bar{F}_{1}(x) d V_{e i}^{1}(x)+\delta_{i}\left(V_{u i}-V_{e i}^{1}(w)\right)
\end{aligned}
$$

which when differentiated with respect to $w$ yields:

$$
h_{1}\left(1-T_{i}^{1 \prime}\left(w h_{1}\right)\right)=\left(\delta_{i}+\rho_{i}+\lambda_{e i}^{0} \bar{F}_{0}\left(q_{i}(w)\right)+\lambda_{e i}^{1} \bar{F}_{1}(w)\right) V_{e i}^{1^{\prime}}(w) .
$$

We denote $\phi_{i}$ as the lowest acceptable wage offer for full-time work. Since $V_{u i}=V_{e i}^{1}\left(\phi_{i}\right)=$ $V_{e i}^{0}\left(q_{i}\left(\phi_{i}\right)\right)$, the lowest acceptable wage offer for part-time work is then $q_{i}\left(\phi_{i}\right)$. Using this, we can write equation $S_{1}$ as:

$$
\rho_{i} V_{u i}=b-T_{i}^{u}+\lambda_{u i}^{0} \int_{q_{i}\left(\phi_{i}\right)}^{\bar{w}_{0}} \bar{F}_{0}(w) d V_{e i}^{0}(w)+\lambda_{u i}^{1} \int_{\phi_{i}}^{\bar{w}_{1}} \bar{F}_{1}(w) d V_{e i}^{1}(w) .
$$

Substituting the envelope conditions $V_{e i}^{1^{\prime}}(w)$ and $V_{e i}^{0^{\prime}}(w)=V_{e i}^{1^{\prime}}\left(q^{-1}(w)\right) / q_{i}^{\prime}(w)$ in to the above:

$$
\begin{aligned}
\rho_{i} V_{u i}=b-T_{i}^{u} & +\lambda_{u i}^{0} \int_{q_{i}\left(\phi_{i}\right)}^{\bar{w}_{0}} \frac{h_{0}\left(1-T_{i}^{0 \prime}\left(w h_{0}\right)\right) \bar{F}_{0}(w)}{\delta_{i}+\rho_{i}+\lambda_{e i}^{0} \bar{F}_{0}(w)+\lambda_{e i}^{1} \bar{F}_{1}\left(q_{i}^{-1}(w)\right)} d w \\
& +\lambda_{u i}^{1} \int_{\phi_{i}}^{\bar{w}_{1}} \frac{h_{1}\left(1-T_{i}^{1 \prime}\left(w h_{1}\right)\right) \bar{F}_{1}(w)}{\delta_{i}+\rho_{i}+\lambda_{e i}^{0} \bar{F}_{0}\left(q_{i}(w)\right)+\lambda_{e i}^{1} \bar{F}_{1}(w)} d w .
\end{aligned}
$$


By definition of the reservation wage we can set the above equal to $\rho_{i} V_{e i}^{1}\left(\phi_{i}\right)$ (from equation S2) to obtain the following implicit equation defining $\phi_{i}$ :

$$
\begin{aligned}
\phi_{i} h_{1}-T_{i}^{1}\left(\phi_{i} h_{1}\right)-C_{i}^{1}=b-T_{i}^{u} & +\left(\lambda_{u i}^{0}-\lambda_{e i}^{0}\right) \int_{q_{i}\left(\phi_{i}\right)}^{\bar{w}_{0}} \frac{h_{0}\left(1-T_{i}^{0 \prime}\left(w h_{0}\right)\right) \bar{F}_{0}(w)}{\delta_{i}+\rho_{i}+\lambda_{e i}^{0} \bar{F}_{0}(w)+\lambda_{e i}^{1} \bar{F}_{1}\left(q_{i}^{-1}(w)\right)} d w \\
& +\left(\lambda_{u i}^{1}-\lambda_{e i}^{1}\right) \int_{\phi_{i}}^{\bar{w}_{1}} \frac{h_{1}\left(1-T_{i}^{1 \prime}\left(w h_{1}\right)\right) \bar{F}_{1}(w)}{\delta_{i}+\rho_{i}+\lambda_{e i}^{0} \bar{F}_{0}\left(q_{i}(w)\right)+\lambda_{e i}^{1} \bar{F}_{1}(w)} d w .
\end{aligned}
$$

Dividing both the numerator and denominator of the integral terms by $\delta_{i}$, and performing a simple change of variable, we then obtain the simplified expression presented in equation 2 in the main text.

\section{Proof of Proposition 4}

The number of individuals who exit either a full-time job paying a wage no-greater than $w$ or a part-time job paying wage no-greater than $q_{i}(w)$ must exactly equal the number of individuals who exit the unemployment pool to receive such wages. That is:

$$
\begin{aligned}
& {\left[m_{1 i} G_{1 i}(w)+m_{0 i} G_{0 i}\left(q_{i}(w)\right)\right] \mathcal{D}_{e i}(w)} \\
& \quad=\lambda_{u i}^{0} u_{i} \int_{-\infty}^{w}\left(F_{0}\left(q_{i}(w)\right)-F_{0}\left(q_{i}(x)\right) d A_{u i}(x)+\lambda_{u i}^{1} u_{i} \int_{-\infty}^{w}\left(F_{1}(w)-F_{1}(x)\right) d A_{u i}(x) .\right.
\end{aligned}
$$

The RHS of equation S6 may be written as:

$$
\begin{aligned}
\lambda_{u i}^{0} u_{i} \int_{-\infty}^{w} \bar{F}_{0}\left(q_{i}(x)\right) d A_{u i}(x)+\lambda_{u i}^{1} u_{i} \int_{-\infty}^{w} \bar{F}_{1}(x) & d A_{u i}(x) \\
- & {\left[\lambda_{u i}^{0} \bar{F}_{0}\left(q_{i}(w)\right)+\lambda_{u i}^{1} \bar{F}_{1}(w)\right] u_{i} A_{u i}(w), }
\end{aligned}
$$

or equivalently by using equations 3 and 4 from the main text as,

$$
\delta_{i} A_{i}(w)-u_{i} A_{u i}(w)\left[\delta_{i}+\mathcal{D}_{u i}(w)\right]
$$

Setting equation $S_{7}$ equal to the LHS of equation $\mathrm{S} 6$ and rearranging terms, we then obtain the form presented in equation 7 from the main text. 


\section{Identification}

In Section 3.2 we discussed the identification of our model, and we now illustrate these ideas more formally. Here we set out to show that conditional on the set of transitional parameters, the observed distributions of part-time and full-time wages, together with the distributions of wages accepted by the unemployed are sufficient to separately identify the wage offer and reservation wage distributions. Once these are known, the structure of the model then permits identification of the opportunity cost and productivity distributions. In what follows, we let $G_{1 i}^{U}$ and $G_{0 i}^{U}$ denote the respective cumulative distribution functions of wages first accepted by type $i$ unemployed workers in full-time and part-time jobs. Since individuals will accept any wage offer that is at least as high as their reservation wage, $G_{1 i}^{U}$ will be given by:

$$
\begin{aligned}
G_{1 i}^{U}(w)=\int_{-\infty}^{w} \operatorname{Pr}\left(W_{1}<w \mid W_{1}>x\right) d A_{u i}(x) & =\int_{-\infty}^{w} \frac{F_{1}(w)-F_{1}(x)}{\bar{F}_{1}(x)} d A_{u i}(x) \\
& =A_{u i}(w)-\bar{F}_{1}(w)\left[\int_{\underline{w}}^{w} \frac{d A_{u i}(x)}{\bar{F}_{1}(x)}+A_{u i}(\underline{w})\right] .
\end{aligned}
$$

Similarly the fraction of part-time jobs accepted that pay no more than $q_{i}(w)$ can be shown to be given by:

$$
G_{0 i}^{U}\left(q_{i}(w)\right)=A_{u i}(w)-\bar{F}_{0}\left(q_{i}(w)\right)\left[\int_{\underline{w}}^{w} \frac{d A_{u i}(x)}{\bar{F}_{0}\left(q_{i}(x)\right)}+A_{u i}(\underline{w})\right] .
$$

If we combine the above two expressions with the respective density functions of accepted wages $g_{h i}^{U} \equiv G_{h i}^{U \prime}$ we can write:

$$
A_{u i}\left(w ; F_{0}\right)=G_{0 i}^{U}\left(q_{i}(w)\right)+\frac{\bar{F}_{0}\left(q_{i}(w)\right) g_{0 i}^{U}\left(q_{i}(w)\right)}{f_{0}\left(q_{i}(w)\right)}
$$

and:

$$
A_{u i}\left(w ; F_{1}\right)=G_{1 i}^{U}(w)+\frac{\bar{F}_{1}(w) g_{1 i}^{U}(w)}{f_{1}(w)},
$$

which therefore demonstrates that the distribution of reservation wages amongst the unemployed on support $\left[\underline{\omega}_{i}, \bar{\omega}_{i}\right]$ is identified given knowledge of the wage offer functions $F_{0}$ and $F_{1}$. The monetary disutility of full-time work $C_{i}^{1}$ is identified by observing how the job-to-job transitions across hours sectors varies with the current wage rate. 
Substituting equations S8 and S9 into equation 6 from the main text, we can eliminate the unobserved reservation wage distribution to obtain the following differential equations governing the evolution of the two wage offer distributions:

$$
\begin{aligned}
F_{1}^{\prime}(w) & =m_{1 i} g_{1 i}(w) R_{i}^{1}\left(w ; F_{0}, F_{1}\right) \\
F_{0}^{\prime}\left(q_{i}(w)\right) & =m_{0 i} g_{0 i}\left(q_{i}(w)\right) R_{i}^{0}\left(w ; F_{0}, F_{1}\right)
\end{aligned}
$$

where:

$$
R_{i}^{1}\left(w ; F_{0}, F_{1}\right) \equiv \frac{\left(1+\kappa_{e i}^{0} \bar{F}_{0}\left(q_{i}(w)\right)+\kappa_{e i}^{1} \bar{F}_{1}(w)\right)-u_{i} g_{1 i}^{U}(w) \kappa_{u i}^{1} \bar{F}_{1}(w)}{\kappa_{u i}^{1} u_{i} G_{1 i}^{U}(w)+\kappa_{e i}^{1}\left(m_{0 i} G_{0 i}\left(q_{i}(w)\right)+m_{1 i} G_{1 i}(w)\right)}
$$

and:

$$
R_{i}^{0}\left(w ; F_{0}, F_{1}\right) \equiv \frac{\left(1+\kappa_{e i}^{0} \bar{F}_{0}\left(q_{i}(w)\right)+\kappa_{e i}^{1} \bar{F}_{1}(w)\right)-u_{i} g_{0 i}^{U}\left(q_{i}(w)\right) \kappa_{u i}^{0} \bar{F}_{0}\left(q_{i}(w)\right)}{\kappa_{u i}^{0} u_{i} G_{0 i}^{U}\left(q_{i}(w)\right)+\kappa_{e i}^{0}\left(m_{0 i} G_{0 i}\left(q_{i}(w)\right)+m_{1 i} G_{1 i}(w)\right)} .
$$

Equations Sio and SiI define a system of differential equations, which together with the initial conditions $F_{1}\left(\underline{\omega}_{i}\right)=0$ and $F_{0}\left(q_{i}\left(\underline{\omega}_{i}\right)\right)=0$, establishes non-parametric identification of both wage offer functions conditional on the set of transitional parameters. Identification of the underlying opportunity cost distribution and the productivity distributions then follows as described in Section 3.3.

\section{E Tax Schedule Smoothing}

Conditional on hours of work $h$, we remove small discontinuities in the budget constraint by setting the minimum transfer amount to zero for all benefits. We also remove the National Insurance (payroll tax) entry fee that existed prior to April 1999. With $K$ tax brackets, the marginal tax rate approximation at hours $h$ and earnings wh for an individual of demographic type $i$ is given by:

$$
\operatorname{MTR}_{i}^{h}(w h)=\sum_{k=1}^{K}\left[\Phi_{i, k}^{h}(w h)-\Phi_{i, k+1}^{h}(w h)\right] \tau_{i, k}^{h}(w h),
$$

where $\tau_{i, k}^{h}$ is the marginal tax rate at the $k^{\text {th }}$ bracket and $\Phi_{i, k}^{h}$ is the normal cumulative distribution function with a mean equal to the value of the $k^{\text {th }}$ tax bracket and with standard deviation $\sigma_{i, k}^{h}$. The value of $\sigma_{i, k}^{h}$ determines how quickly the smoothed marginal tax rates $M T R_{i}^{h}$ change in the neighborhood of the break points, with a small value 
fitting the underlying step function more closely. We set $\sigma_{i, k}^{h}=20$ (measured in pounds per week in April 1997 prices) which produces a relatively smooth tax schedule, but our results are not sensitive to this choice.

\section{F Numerical Algorithm}

We now sketch the algorithm that we use to solve for the steady state equilibrium:

1. We first provide an initial guess of the recruiting policy functions $v_{h}(p)$ and unemployment shares $u_{i}$ to obtain the total recruiting intensity $V_{h}$ and total search intensity $S_{h}$. Given a parametrization of the matching functions, we can use equation 17 from the main text to obtain a set of arrival rates $\lambda_{j i}^{h}$.

2. Conditional upon the guesses from step 1, we solve for the optimal wage policy of firms $w_{h}(p)$. To do this we first provide an initial guess of the wage policy functions (with $w_{h}(p)<p$ strictly increasing in $p$ ), and using the relationship between the (weighted) distribution of firm productivity and wage offers in equation 18 , solve for the steady state of the labor market using the flow equations presented in Section 2 from the main text. To obtain an update of $\pi_{h}^{*}\left(\underline{p}_{h}\right)$ we calculate $\tilde{w}_{h}=$ $\arg \max _{w}\left(\underline{p}_{h}-w\right) L_{h}(w)$ and then set $\pi_{h}^{*}\left(\underline{p}_{h}\right)=\left(\underline{p}_{h}-\tilde{w}_{h}\right) L_{h}(\underline{w})$. We then obtain an update of the wage policy functions by using equation 15 from the main text. We continue to iterate until (conditional on our guess of the recruiting policy functions and arrival rates) the wage policy functions of both part-time and full-time firms converge.

3. Given the wage policy functions from step 2, we update our guess of the recruiting policy functions by using equation 13 from the main text. We then return to step 1 above, with these updated recruiting policy functions (together with the implied unemployment rates $u_{i}$ from step 2) replacing our initial guesses. We keep repeating this iterative procedure until the recruiting policy functions of both part-time and full-time firms has converged.

\section{G Proof of Reform Invariance to Parametrization of $c_{h}(p)$}

Under the assumption that $c_{h}(p, v)=c_{h}(p) v^{2}$, the equilibrium of the model is invariant to the parametrization of $c_{h}(p)$ provided that $c_{h}(p)>0$ for all $p$. To understand this 
invariance result let us consider the pair of recruiting cost functions $c_{h}(p)$ and $\tilde{c}_{h}(p)$ for $h \in\{0,1\}$. In each case, we recover the distribution of firm productivity and underlying search intensities such that under the base system we induce the estimated set of arrival rates and wage offer distributions. To demonstrate this result, we show that given a set of job offer arrival rates the optimal choice of wage policy functions and distribution of wage offers are the same. We then show that given the optimal choice of recruiting intensity, both cost functions generate the same equilibrium job offer arrival rates.

First note that in order to induce the same distributions of wage offers under the base system, the distributions of firm productivity under the alternative cost function must satisfy:

$$
\tilde{\gamma}_{h}(p)=\frac{\gamma_{h}(p) \tilde{c}_{h}(p) \tilde{V}_{h, b}^{2}}{c_{h}(p) V_{h, b}^{2}}
$$

In equation $\mathrm{S}_{12}$ and in what follows, we denote objects under the alternative cost function $\tilde{c}_{h}(p)$ with a tilde. Similarly, $V_{h, b}$ and $\tilde{V}_{h, b}$ are used to denote the respective aggregate recruiting intensities under the base systems.

We now demonstrate that we obtain the same distribution of wage offers following the tax reform under $\tilde{c}_{h}(p)$ with the alternative recruiting policy function $\tilde{v}_{h}(p)$ as given by:

$$
\tilde{v}_{h}(p)=\frac{c_{h}(p) v_{h}(p) V_{h}}{\tilde{c}_{h}(p) \tilde{V}_{h}}
$$

This recruiting policy function is consistent with the same expected profit flow per unit intensity under the alternative cost functions (see equation 13 from the main text). This choice of recruiting policy also induces the same wage offer distributions. Using equation $S_{12}$ and equation $S_{13}$ :

$$
\begin{aligned}
\tilde{F}\left(w_{h}(p)\right) & =\int_{\underline{p}_{h}}^{p} \frac{\tilde{v}_{h}(p) d \tilde{\Gamma}_{h}(p)}{\tilde{V}_{h}} \\
& =\int_{\underline{p}_{h}}^{p} \frac{c_{h}(p) v_{h}(p) V_{h} d \tilde{\Gamma}_{h}(p)}{\tilde{c}_{h}(p) \tilde{V}_{h}^{2}} \\
& =\left(\frac{V_{h} / V_{h, b}}{\tilde{V}_{h} / V_{h, b}}\right)^{2} \int_{\underline{p}_{h}}^{p} \frac{v_{h}(p) d \Gamma_{h}(p)}{V_{h}} \\
& =F\left(w_{h}(p)\right),
\end{aligned}
$$


with the final equality following from the observation that:

$$
\tilde{V}_{h}=\int_{\underline{p}_{h}}^{\bar{p}_{h}} \tilde{v}_{h}(p) d \tilde{\Gamma}(p)=\int_{\underline{p}_{h}}^{\bar{p}_{h}} \frac{c_{h}(p) v_{h}(p) V_{h} d \tilde{\Gamma}_{h}(p)}{\tilde{c}_{h}(p) \tilde{V}_{h}}=\left(\frac{V_{h}}{\tilde{V}_{h}} \cdot \frac{\tilde{V}_{h, b}^{2}}{V_{h, b}^{2}}\right) \int_{\underline{p}_{h}}^{\bar{p}_{h}} v_{h}(p) d \Gamma_{h}(p),
$$

so that the aggregate recruiting intensity ratio in the reform and base systems is the same irrespective of the cost function parametrization:

$$
\frac{V_{h}}{V_{h, b}}=\frac{\tilde{V}_{h}}{\tilde{V}_{h, b}}
$$

Finally, we verify that the set of job offer arrival rates are the same by showing that the set of search intensities that would induce these arrival rates do not change between the base and reform systems. Note that the arrival rates must satisfy:

$$
\lambda_{j i}^{h}=s_{j i}^{h}\left[\frac{V_{h}}{M_{h}}\right]^{\frac{\theta_{h}}{1-\theta_{h}}}
$$

and that if the set of arrival rates are the same then so is the flow of matches. Thus, we obtain the same set of arrival rates with the alternative cost functions if:

$$
\frac{s_{j i}^{h}}{\tilde{s}_{j i}^{h}}=\left[\frac{V_{h}}{\tilde{V}_{h}}\right]^{\frac{\theta_{h}}{1-\theta_{h}}} .
$$

From equation S15 we know that $V_{h} / \tilde{V}_{h}=V_{h, b} / \tilde{V}_{h, b}$ so that there is no change in this ratio between the base and reform systems. 